\title{
Disturbed gut microbiota and bile homeostasis in Giardia-infected mice contributes to metabolic dysregulation and growth impairment
}

Citation for published version (APA):

Riba, B., Hassani, K., Walker, A., van Best, N., von Zeschwitz, D., Anslinger, T., Sillner, N., Rosenhain, S., Eibach, D., Maiga-Ascofare, O., Rolle-Kampczyk, U., Basic, M., Binz, A., Mocek, S., Sodeik, B., Bauerfeind, R., Mohs, A., Trautwein, C., Kiessling, F., ... Hornef, M. W. (2020). Disturbed gut microbiota and bile homeostasis in Giardia-infected mice contributes to metabolic dysregulation and growth impairment. Science Translational Medicine, 12(565), [7019].

https://doi.org/10.1126/scitrans/med.aay7019

Document status and date:

Published: 14/10/2020

DOI:

10.1126/scitransImed.aay7019

Document Version:

Publisher's PDF, also known as Version of record

Document license:

Taverne

Please check the document version of this publication:

- A submitted manuscript is the version of the article upon submission and before peer-review. There can be important differences between the submitted version and the official published version of record.

People interested in the research are advised to contact the author for the final version of the publication, or visit the DOI to the publisher's website.

- The final author version and the galley proof are versions of the publication after peer review.

- The final published version features the final layout of the paper including the volume, issue and page numbers.

Link to publication

\footnotetext{
General rights rights.

- You may freely distribute the URL identifying the publication in the public portal. please follow below link for the End User Agreement:

www.umlib.nl/taverne-license

Take down policy

If you believe that this document breaches copyright please contact us at:

repository@maastrichtuniversity.nl

providing details and we will investigate your claim.
}

Copyright and moral rights for the publications made accessible in the public portal are retained by the authors and/or other copyright owners and it is a condition of accessing publications that users recognise and abide by the legal requirements associated with these

- Users may download and print one copy of any publication from the public portal for the purpose of private study or research.

- You may not further distribute the material or use it for any profit-making activity or commercial gain

If the publication is distributed under the terms of Article $25 \mathrm{fa}$ of the Dutch Copyright Act, indicated by the "Taverne" license above, 


\section{Disturbed gut microbiota and bile homeostasis in Giardia-infected mice contributes to metabolic dysregulation and growth impairment}

\author{
Ambre Riba ${ }^{1}$, Kasra Hassani ${ }^{2}$, Alesia Walker ${ }^{3}$, Niels van Best ${ }^{1,4}$, Dunja von Zeschwitz ${ }^{1}$, \\ Teresa Anslinger ${ }^{1}$, Nina Sillner ${ }^{3,5}$, Stefanie Rosenhain ${ }^{6}$, Daniel Eibach ${ }^{7}$, Oumou Maiga-Ascofaré ${ }^{8}$, \\ Ulrike Rolle-Kampczyk ${ }^{9}$, Marijana Basic ${ }^{10}$, Anne Binz ${ }^{11}$, Sabine Mocek ${ }^{12}$, Beate Sodeik ${ }^{11}$, \\ Rudolf Bauerfeind $^{13}{ }^{3}$ Antje Mohs ${ }^{14}$, Christian Trautwein ${ }^{14}$, Fabian Kiessling ${ }^{6,15,16}$, Jürgen May ${ }^{7}$, \\ Martin Klingenspor ${ }^{12}$, Felix Gremse ${ }^{6,17,18}$, Philippe Schmitt-Kopplin ${ }^{3,5,19}$, André Bleich ${ }^{10}$, \\ Natalia Torow ${ }^{1}$, Martin von Bergen ${ }^{9,20}$, Mathias W. Hornef ${ }^{1 *}$
}

\begin{abstract}
Although infection with the human enteropathogen Giardia lamblia causes self-limited diarrhea in adults, infant populations in endemic areas experience persistent pathogen carriage in the absence of diarrhea. The persistence of this protozoan parasite in infants has been associated with reduced weight gain and linear growth (height-for-age). The mechanisms that support persistent infection and determine the different disease outcomes in the infant host are incompletely understood. Using a neonatal mouse model of persistent $G$. lamblia infection, we demonstrate that $\mathrm{G}$. lamblia induced bile secretion and used the bile constituent phosphatidylcholine as a substrate for parasite growth. In addition, we show that $G$. lamblia infection altered the enteric microbiota composition, leading to enhanced bile acid deconjugation and increased expression of fibroblast growth factor 15 . This resulted in elevated energy expenditure and dysregulated lipid metabolism with reduced adipose tissue, body weight gain, and growth in the infected mice. Our results indicate that this enteropathogen's modulation of bile acid metabolism and lipid metabolism in the neonatal mouse host led to an altered body composition, suggesting how G. lamblia infection could contribute to growth restriction in infants in endemic areas.
\end{abstract}

\section{INTRODUCTION}

Giardia lamblia, also named Giardia intestinalis or Giardia duodenalis, is a major cause of diarrheal disease worldwide, estimated to lead to about 280 million annual cases (1). Oral administration to study volunteers, outbreak descriptions, and disease occurrence in travelers to endemic areas have highlighted G. lamblia's pathogenic potential in causing episodes of diarrhea, vomiting, abdominal pain, and anorexia $(2,3)$. For most patients, the disease is acute and self-limiting, although some individuals experience prolonged diar-

\footnotetext{
'Institute of Medical Microbiology, RWTH University Hospital, 52074 Aachen, Germany. ${ }^{2}$ Institute of Medical Microbiology and Hospital Epidemiology, Hannover Medical School, 30625 Hannover, Germany. ${ }^{3}$ Research Unit Analytical BioGeoChemistry, Helmholtz Zentrum München, 85764 Neuherberg, Germany. ${ }^{4}$ Department of Medical Microbiology and NUTRIM, Maastricht University, Maastricht, Netherlands. ${ }^{5}$ ZIEL Institute for Food and Health, Technical University of Munich, 85354 Freising, Germany. ${ }^{6}$ Institute for Experimental Molecular Imaging, University Hospital Aachen, 52074 Aachen, Germany. ${ }^{7}$ Department of Infectious Disease Epidemiology, Bernhard Nocht Institute for Tropical Medicine, 20359 Hamburg, Germany. ${ }^{8}$ Kumasi Centre for Collaborative Research in Tropical Medicine, Kumasi, Ghana. ${ }^{9} \mathrm{Helmholtz}$ Centre for Environmental Research, Department of Molecular Systems Biology, 04318 Leipzig, Germany. ${ }^{10}$ Institute for Laboratory Animal Science, Hannover Medical School, 30625 Hannover, Germany. ${ }^{11}$ Institute of Virology, Hannover Medical School, 30625 Hannover, Germany. ${ }^{12}$ Chair for Molecular Nutritional Medicine, School of Life Sciences, Technical University of Munich, 85354 Freising, Germany. ${ }^{13}$ Research Core Unit for Laser Microscopy, Hannover Medical School, 30625 Hannover, Germany. ${ }^{14}$ Medizinische Klinik III, RWTH University Hospital, Aachen, 52074 Aachen, Germany. ${ }^{15} \mathrm{Helm}$ holtz Institute for Biomedical Engineering, RWTH Aachen University, Aachen, Germany. ${ }^{16}$ Fraunhofer Institute for Digital Medicine MEVIS, Bremen, Germany. ${ }^{17}$ Software Tools for Computational Engineering, RWTH Aachen University, 52072 Aachen, Germany. ${ }^{18}$ Gremse-IT GmbH, 52068 Aachen, Germany.

${ }^{19}$ Analytical Food Chemistry, Technical University of Munich, 85354 Freising, Germany.

${ }^{20}$ Institute of Biochemistry, Faculty of Life Sciences, University of Leipzig, Brüderstraße 34, D-04103 Leipzig, Germany.

*Corresponding author. Email: mhornef@ukaachen.de
}

rhea with malabsorption $(3,4)$. In notable contrast, several longitudinal studies have shown that G. lamblia infection in children in endemic areas is not associated with acute diarrheal disease (5-8). The presence of G. lamblia, at least in some areas, may even diminish the likelihood of having acute moderate to severe diarrhea (9-11). Initial G. lamblia infection in early infancy may rather be associated with persistent ( $>14$ days) disease (8). Three recent prospective human studies identified the presence of G. lamblia in infant stool samples as an independent risk factor for reduced linear growth $(7,10,12)$. In particular, exposure to G. lamblia during an early neonatal window was associated with reduced weight-for-height and weight-for-age (13). An unsafe water supply and insufficient sanitation support parasite transmission and may explain the high prevalence of G. lamblia in infant stool samples and rapid reinfections after drug-induced cure $(10,11,14,15)$.

Despite epidemiological evidence for an association between persistent or recurrent $G$. lamblia infection and reduced linear growth in infants, a causal relationship has not been established and the underlying mechanisms remain incompletely understood (16-18). G. lamblia infection is associated with increased intestinal permeability (10). Alterations in the mucosal permeability of the gut have been associated with impaired growth in later life and might thus represent a causal link (19). However, a multitude of possible confounders including malnutrition and immune impairment, phylogenetic differences of G. lamblia strains, coinfections with other enteropathogens, and undernutrition-associated changes in the gut microbiota composition may critically influence infection susceptibility and disease outcomes, complicating the interpretation of the reported epidemiological findings in humans. Furthermore, preclinical models indicate not only that G. lamblia coinfection can 
promote malnutrition and growth impairment but also that malnutrition aggravates the course of G. lamblia infection (20-22).

Here, we used a mouse model of persistent G. lamblia infection after trophozoite administration to healthy neonatal mice (22-24). Persistent infection led to reduced body weight gain and linear growth impairment in the absence of an impaired gut mucosal barrier, thus mimicking the phenotype of endemic G. lamblia infection in human infants. We deployed transcriptional profiling, microbiome and metabolome analysis, and whole-body imaging to investigate the underlying mechanism of pathogen persistence in the mouse small intestine after neonatal host infection and metabolic dysregulation during persistent infection.

\section{RESULTS \\ Age-dependent susceptibility to persistent \\ G. Iamblia infection}

The high carriage rate of G. lamblia among children in endemic areas and the unexplained association with reduced weight gain and growth prompted us to comparatively investigate the consequences of oral $G$. lamblia infection in mice of different ages $(7,8,10)$. Consistent with previous reports, healthy 4 -week-old adult animals infected with $G$. lamblia trophozoites cleared the infection within 2 to 3 weeks $(25,26)$. Only the administration of $G$. lamblia cysts (H3 strain) was reported to induce prolonged infection in healthy adult animals (21). In notable contrast, mice infected as neonates exhibited persistent carriage with stable parasite counts and prolonged antigen shedding $(P<0.05)$ (Fig. $1 \mathrm{~A}$ and fig. S1A). Mice infected at the age of 2 weeks exhibited an intermediate phenotype, defining the postnatal window as the age of enhanced vulnerability (fig. S1B). Prolonged monitoring revealed that C57BL/6J mice infected as neonates (3-day-old mice) remained G. lamblia positive for more than 20 weeks, at which point they started to spontaneously clear the infection (Fig. 1B).

We next characterized the parasite's organ tropism and the host's mucosal response to infection. Histological and ultrastructural analysis illustrated dense colonization of the proximal small intestine and intimate interaction between the protozoan and the intestinal epithelium's apical membrane at both 1 and 4 weeks post-infection (p.i.) (Fig. 1, C and D). Trophozoite counts and quantitative polymerase chain reaction (PCR) readily detected G. lamblia in the small intestine's luminal contents during the course of the infection with maximum abundance in the proximal part of the small intestine, as reported in humans (Fig. 1, E and F). Despite the parasite's continuous presence, however, we observed neither inflammatory phagocytes, mast cell recruitment, nor functionally impaired epithelial barrier integrity in persistently infected adult animals (Fig. 2, A to D, and fig. S2A).

Nevertheless, persistent infection was associated with reduced body size $(P<0.001)$ and weight gain $(P<0.001)$ (Fig. $2, \mathrm{E}$ to $\mathrm{G}$, and fig. S2, B and C), and this phenotype lasted throughout adulthood $(P<0.05)$ (Fig. $2 \mathrm{H})$. Although we noted moderately elevated intestinal fluid and fecal humidity in infected animals $(P<0.05$ and $P<0.01$ ) (Fig. 2I), careful analysis of the propulsive bowel movements (Fig. 2J), food intake (Fig. 2K), energy absorption (Fig. 2L), and body weight gain $(P<0.01)$ (Fig. $2 \mathrm{M})$ clearly demonstrated that the reduced weight gain in G. lamblia-infected animals was not due to reduced food intake, diminished passage time, or impaired energy absorbance from ingested food. Thus, in addition to the enhanced susceptibility of malnourished adult animals to G. lamblia infection (21), infection of healthy neonate mice led to prolonged parasite persistence. Parasite persistence contributed to reduced weight gain and impaired linear growth that was not explained by the results from the analyses of mucosal barrier function (Fig. 2, C and D).

\section{Identification of host factors driving G. Iamblia persistence}

Animals infected neonatally did not clear the parasite when they reached adulthood, although naive adult animals exposed to G. lamblia were resistant to infection. This suggested that the parasite manipulated the host during the postnatal period to favor persistence. However, the intestines of G. lamblia-infected adult animals revealed no apparent histopathological or immunological alteration, immune cell infiltration, or impaired barrier function (Figs. 1D and 2, A to D).

Careful investigation at autopsy revealed markedly fewer filled gall bladders in infected (30\%) versus healthy age-matched control animals $(80 \%$; $P<0.05)$ (Fig. $3, \mathrm{~A}$ and $\mathrm{B})$. Transcriptional and mass spectrometric analyses of liver tissue excluded reduced bile synthesis in infected animals as an underlying cause (fig. S3, A and B). There were no identifiable changes in the hepatic expression of key enzymes, from both the classical and alternative bile synthesis pathways (fig. S3A). In addition, liver tissue showed no alteration in the concentration of major primary and secondary bile acid species (fig. S3B). Instead, we noted highly elevated mRNA expression of the bile secretion-promoting gut hormone cholecystokinin in the intestinal epithelium of infected animals $(P<0.0001)$ (Fig. 3C). Enhanced bile secretion and enterohepatic circulation were confirmed by elevated blood concentrations of the major unconjugated bile acid components in mice: cholic acid (CA), $\alpha$-murocholic acid ( $\alpha \mathrm{MCA})$ and $\beta$-murocholic acid ( $\beta \mathrm{MCA} ; P<0.01)$ (Fig. 3D).

Bile acids represent a major bile constituent and exert both growth-promoting and antiparasitic activity (27-31). Bile concentrations $>1 \%$ inhibited parasite growth in vitro (Fig. 3E). The peak luminal bile concentrations in the adult host could have impeded infection. However, neither luminal bile acid scavenging via cholestyramine administration in adult mice before and after G. lamblia infection nor repeated oral administration of high bile concentrations in neonatally infected, persistently G. lamblia-positive mice altered the course of the infection (Fig. 3, F and G, and fig. S3C). Conversely, moderately enhanced bile acid concentrations promoted G. lamblia growth in vitro with maximal growth stimulation at $0.1 \%$ bile supplementation, consistent with the original report on the growth-promoting activity of mammalian bile on axenic growth of G. lamblia (Fig. 3E) $(28,31)$. Thus, enhanced bile secretion might contribute to parasite persistence. Both commercially available bovine bile, commonly used as medium supplement, and murine bile obtained by gall bladder puncture enhanced the in vitro growth rate of G. lamblia trophozoites (Fig. 3H). The taurine-conjugated bile acid species taurocholic acid (TCA), most abundantly found in liver and proximal intestinal tissue, exerted a particularly strong growth-promoting effect (Fig. 3I). However, comparative mass spectrometric analysis of conditioned medium after 24 hours of parasite culture with fresh growth medium revealed no detectable consumption of murine or bovine bile acids by G. lamblia (Fig. 3J and fig. S3D). This indicated that bile acids promoted G. lamblia growth but did not represent an energy source for the parasite in vivo in our experiments. 
A

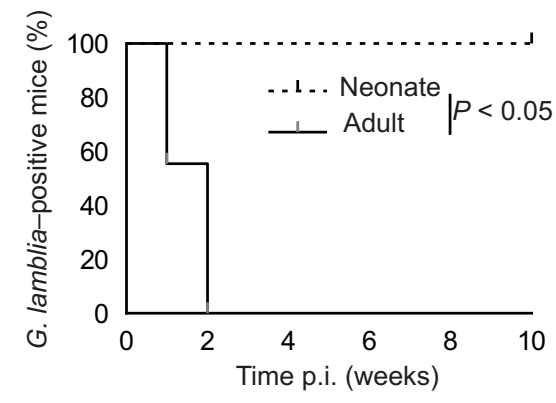

B

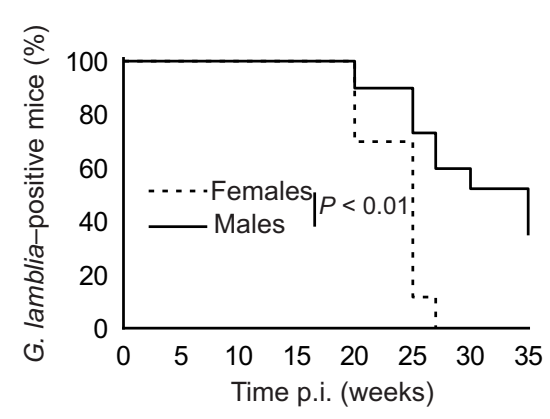

E

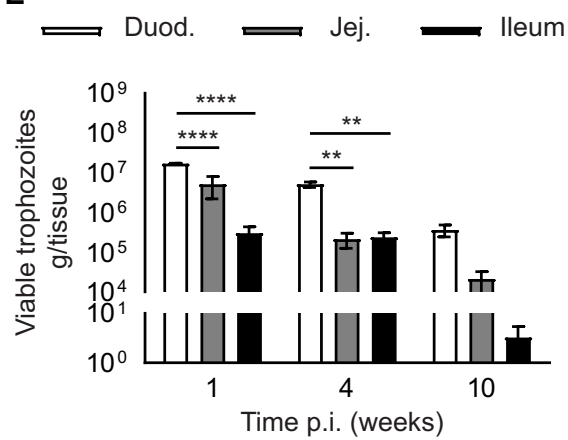

C

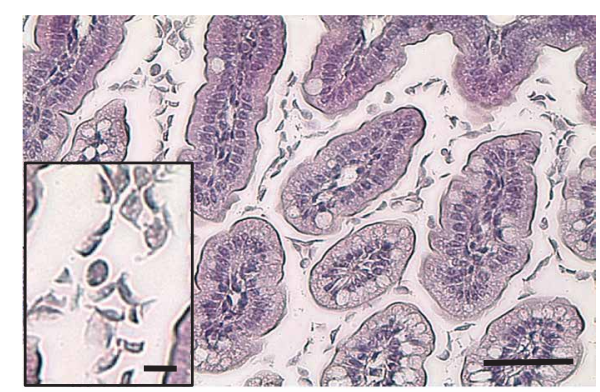

D

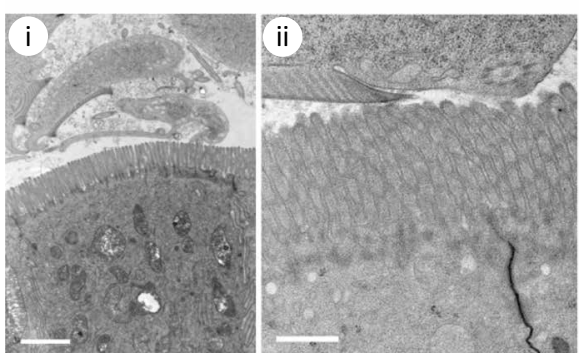

$\mathbf{F}$

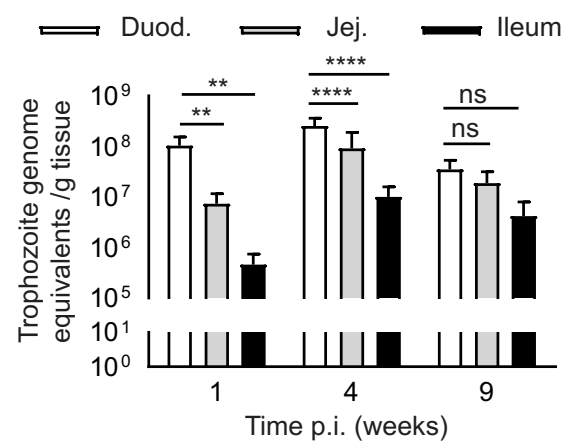

Fig. 1. Neonatal mice infected with G. lamblia show persistent infection. (A) Three-day-old (neonate) or 4-weekold (adult) mice were orally infected with $2 \times 10^{5}$ (neonates) or $1 \times 10^{7}$ (adults) trophozoites of G. lamblia. The presence of $G$. lamblia antigen in fecal material was monitored weekly post-infection (p.i.) $(n=11$ per group from two to three litters). (B) Three-day-old male and female mice were orally infected with G. lamblia trophozoites, and fecal G. lamblia antigen was monitored weekly ( $n=9$ to 10 per group from two litters). (C) Hematoxylin and eosin-stained representative tissue section of the mouse proximal small intestine. Tissue was obtained from mice that had been infected at 3 days of age, at 4 weeks p.i. [ $n=4$ from two litters; scale bar, $25 \mu \mathrm{m}$; scale bar (inset), $5 \mu \mathrm{m}$ ]. (D) Representative transmission electron microscopy images of mouse proximal small intestine. Tissue was obtained from mice that had been infected at 3 days of age, at 8 weeks p.i. [ $n=4$ from two litters; scale bar (left), $500 \mathrm{~nm}$; scale bar (right), $200 \mathrm{~nm}$. (E) Counts of viable trophozoites per gram intestinal tissue in mice infected with $\mathrm{G}$. lamblia at 3 days of age, at 1,4 , and 10 weeks p.i., are shown. Proximal, middle, and distal small intestinal tissues were longitudinally opened and incubated on ice on a shaker for 2 hours at $150 \mathrm{rpm}$. Viable (motile) trophozoites were quantified microscopically in a hemocytometer ( $n=4$ to 5 per group from two litters). (F) Genome equivalents per gram intestinal tissue at 1, 4, and 10 weeks p.i. were quantified by quantitative PCR using the dilution series of a standard with a known number of viable trophozoites ( $n=4$ to 7 per group from two litters). Graphs show means $\pm S D ;{ }^{*} P<0.05,{ }^{* *} P<0.01,{ }^{* * *} P<0.001$, and ${ }^{* * * *} P<0.0001$ by Mantel-Cox test ( $A$ and $B$ ) or two-way ANOVA with Bonferroni post-test ( $E$ and $F$ ). All data are representative of two to three independent in vivo experiments. ns, not significant.

We next searched for other energy-rich constituents in bile that could represent possible metabolic substrates and might promote parasite growth. Decreased concentrations of the lysophosphatidylcholines (LysoPC) 16:0, 18:0, and 18:2 were observed after in vitro culture of G. lamblia $(P<0.01)$ (Fig. 4, A to C, and fig. S4A). Sup-

plementing the growth medium with LysoPC(16:0), LysoPC(18:0), or a mixture of LysoPC(16:0) and LysoPC(18:0) at $0.04 \mathrm{mM}$ consistently enhanced G. lamblia proliferation (Fig. 4D). Several additional in vivo findings supported that LysoPC promoted G. lamblia growth. First, the intestinal epithelial mRNA expression of intestinal phospholipase $\mathrm{A}_{2}$ $\left(\mathrm{PLA}_{2}\right)$, the enzyme responsible for transforming bile-derived phosphatidylcholine (PC) to LysoPC, was higher in G. lamblia-infected animals $(P<0.05)$ (Fig. 4E) (32). Second, the LysoPC concentration was lower in blood samples from infected animals than age-matched healthy controls $(P<0.01)$ (fig. S4B). Third, the susceptibility of adult mice to oral G. lamblia infection was enhanced by orally administered LysoPC alone $(P<0.05)$ and, even more so, in combination with bile, which together resulted in $100 \%$ G. lamblia-positive animals at 4 weeks p.i. $(P<0.01)$ (Fig. 4 F). In contrast, oral administration of the same dose of bile alone did not enhance the susceptibility to infection (Fig. 4F). Last, reduced LysoPC concentrations in bile fluid of multiple drug resistance 2 (Mdr2) gene-deficient mice (33) led to spontaneous clearance in $40 \%$ of neonatally infected mice at the age of 7 weeks (Fig. 4G). Thus, G. lamblia may have induced bile fluid secretion, and bilederived PC converted to LysoPC in combination with conjugated bile acids might have supported parasite growth.

\section{Functional consequences of persistent G. Iamblia infection}

Persistently G. lamblia-infected animals had lower body weights and linear growth after weaning, consistent with associations seen in endemic areas (Fig. 2, F to H) $(7,10)$. Given that reduced linear growth and weight gain in developing countries have previously been associated with altered microbiomes, we next analyzed enteric microbiota composition $(34)$. The small $(P<0.05)$ and large $(P<0.01)$ intestinal microbiota composition differed between G. lambliainfected adult animals and age-matched controls (Fig. 5A). This difference was observed in adult mice but not in neonates (fig. S5A). This result suggested that the G. lamblia-induced alteration of bile secretion or the mucosal adaptive immune system that matured after weaning may represent the underlying mechanism (35). In addition, the luminal presence of the parasite itself might have contributed to the 
Fig. 2. Parasite persistence leads to impaired growth and weight gain in mice. ( $A$ and B) Flow cytometric counts for (A) lamina propria macrophages, monocytes, and polymorphonuclear cells as well as (B) mast cells in the small intestine (SI) of mice infected at 3 days of age with G. lamblia (G.I.) at 4 weeks p.i. compared to age-matched control mice (CTL) ( $n=11$ per group from two litters). (C) Intestinal permeability at 4 weeks p.i. is shown. Fluorescence was quantified in serum samples obtained 4 hours after administration of 4-kDa FITC-dextran by oral gavage of mice infected with $2 \times 10^{5} \mathrm{G}$. lamblia trophozoites at 3 days old compared to healthy age-matched control animals ( $n=6$ to 7 per group from two litters). (D) Serum endotoxin concentrations at 7 weeks p.i. of 3-day-old mice with $2 \times 10^{5} \mathrm{G}$. lamblia (G.I.) trophozoites compared to healthy age-matched control animals. Endotoxin was quantified in 1:10 diluted serum samples using a limulus assay ( $n=3$ to 8 per group from two litters). ( $\mathbf{E}$ and $\mathbf{F}$ ) Body size (nose to tail) of mice infected at 3 days old with $2 \times 10^{5} \mathrm{G}$. lamblia trophozoites (G.I.) at 4 weeks p.i. compared to healthy age-matched control animals (CTL) ( $n=7$ to 9 per group from two litters). ( $\mathbf{G}$ and $\mathbf{H}$ ) Total body weight at 4 weeks p.i. (G) and the time course of body weight between 4 and 20 weeks p.i. $(\mathrm{H})$ for mice infected at 3 days old with G. lamblia compared to age-matched control animals ( $n=7$ to 9 , per group from two litters). (I) Water content in duodenum (Duo), jejunum (Jej), ileum (lle), and colon (Col) tissues as well as in feces at 4 weeks p.i. for mice infected at 3 days old or age-matched control animals ( $n=5$ to 13 per group from two to three litters). (J) Intestinal transit of charcoal 10 and 30 min after oral administration as percentage of total small intestine length is shown. Four-week-old mice infected with $2 \times 10^{5} \mathrm{G}$. lamblia trophozoites at the age of 3 to 4 days (G.I.) or healthy age-matched control animals (CTL) were analyzed ( $n=7$ to 9 per group from two litters). ( $\mathbf{K}$ to $\mathbf{M}$ ) Metabolic energy monitoring of $G$. lambliainfected mice (G.I.) and age-matched control animals (CTL) for (K) total solid food intake per week (g) and (L) energy absorbed from food per week $(\mathrm{kJ})$ as measured by calorimetric analysis of collected feces; also shown is (M) the total body weight increase per week $(\mathrm{g})(n=5$ to 7 per group from two litters). Graphs show means $\pm S D ;{ }^{*} P<0.05,{ }^{* *} P<0.01$, and ${ }^{* * *} P<0.001$ by two-way ANOVA with Bonferroni post-test ( $\mathrm{A}$ and $\mathrm{H}$ to $\mathrm{J}$ ) or Mann-Whitney test ( $\mathrm{B}$ to $D, F, G$, and $K$ to $M$ ). All data are representative of two to three independent in vivo experiments.
A

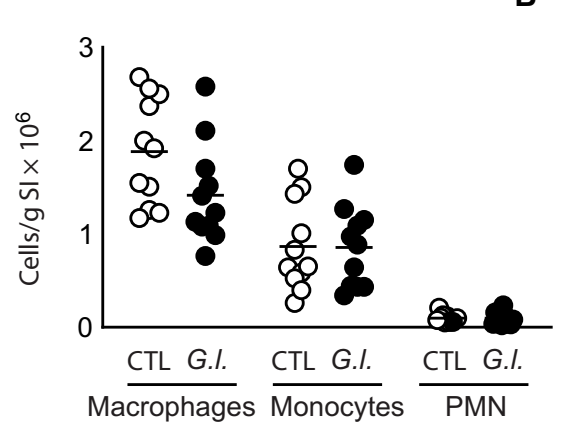

D

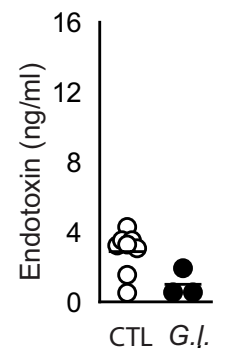

E

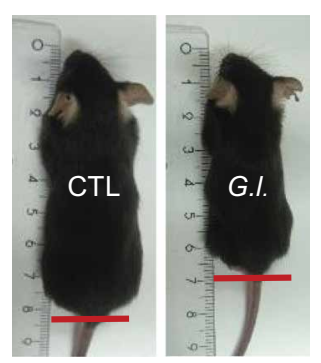

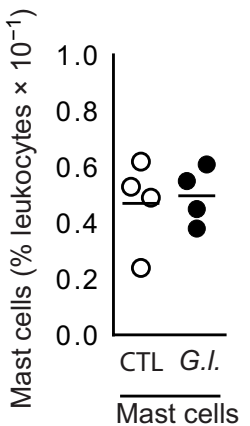

$\mathbf{F}$

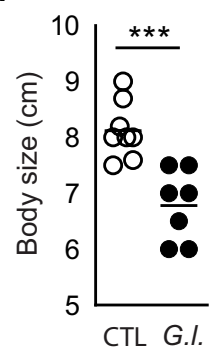

C

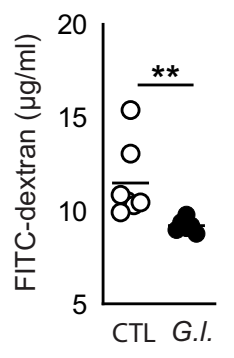

G

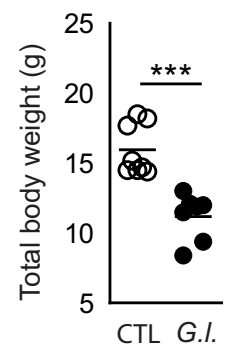

H

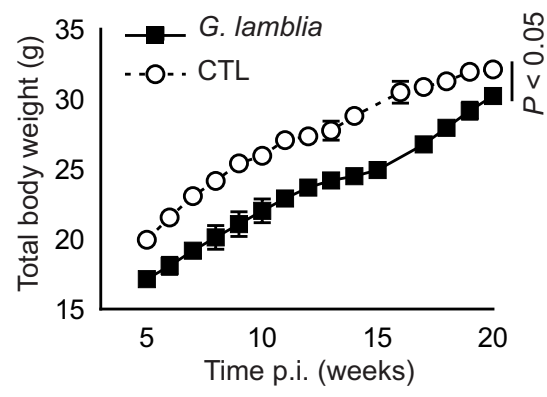

J

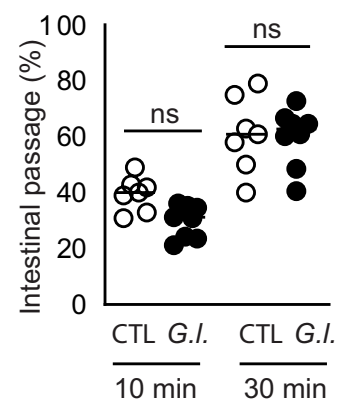

K

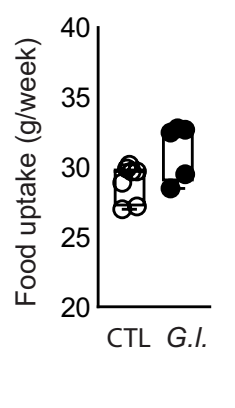

I

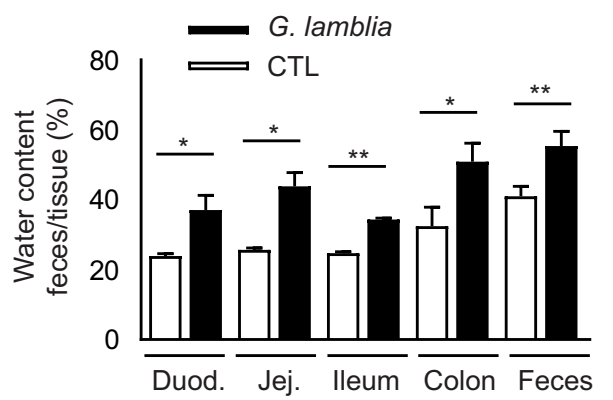

$\mathbf{L}$

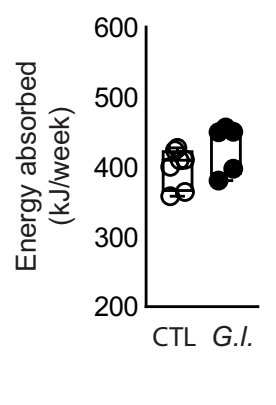

M

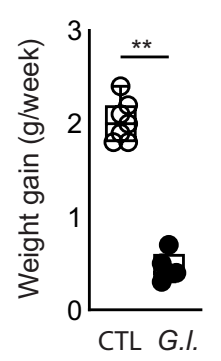

observed changes in the gut microbiota composition (36). To evaluate the altered enteric microbiota's possible role in infected animals' reduced body weight gain, we next transferred large intestinal contents of infected and age-matched control animals by oral gavage to germ-free C57BL/6J mice, using two different approaches. Transferring the enteric microbiota of adult mice during chronic infection or after spontaneous clearance of G. lamblia did not influence the body weight of germ-free recipients (fig. S5, B to E). Comparative analysis in donor and recipient animals confirmed the efficiency of the gut microbiota transfer and the establishment of a highly diverse gut microbiota in the recipient animals (fig. S5, F and G). Thus, the gut microbiota transfer experiments were unable to provide evidence for a direct functional effect of the altered microbiota composition on the reduced growth and weight gain in chronically infected animals.

Analyzing the observed gut microbiota changes after parasite infection revealed a slight increase in bacterial richness in the large 
Fig. 3. Enhanced bile secretion during G. lamblia persistence. (A) Macroscopic view of the abdominal situs of 4-week-old persistently G. lamblia-infected mice (G.I.; right) and healthy control animals (CTL; left). (B) Number of animals with full or empty gall bladders among persistently G. lamblia-infected mice (G. lamblia) or healthy age-matched control animals (CTL) was examined with food ad libitum (normal), after fasting for 12 hours (Fasting 12 hours) or 30 min after a 12-hour fasting period (+ Food $30 \mathrm{~min}$ ) ( $n=5$ to 23 per group from two to four litters). (C) Quantitative RT-PCR for cholecystokinin mRNA expression in intestinal epithelial cells isolated from the small intestine of persistently G. lamblia-infected mice (G.I.) or healthy age-matched control animals (CTL) after fasting for 12 hours (Fasting 12 hours) or $30 \mathrm{~min}$ after a 12-hour fasting period (Food $30 \mathrm{~min}$ ) is shown. Values were normalized to the expression of the housekeeping gene $h p r t$ ( $n=6$ to 11 per group from two to three litters). (D) Quantitative analysis of the concentration of cholic acid (CA) and $\alpha$-murocholic acid and $\beta$-murocholic acid (MCA) in peripheral blood from nonfasted mice 4 weeks p.i. or age-matched nonfasted control animals ( $n=10$ per group from two litters) is shown. (E) G. lamblia trophozoite count after $G$. lamblia incubation in vitro in culture medium supplemented with the indicated concentrations ( $\mathrm{vol} \%$ ) of total bovine bile. The means of two independent technical replicates are shown. (F) Percentage of fecal G. lamblia antigenpositive animals after oral infection of adult mice at the age of 4 weeks with $1 \times 10^{7}$ G. lamblia trophozoites after pretreatment for 1 week with cholestyramine (daily oral gavage of $500 \mathrm{mg} / \mathrm{kg}$ body weight from 1 week before infection until the end of the experiment) or PBS ( $n=7$ per group from two litters). (G) Three-day-old neonatal mice were infected with G. lamblia and treated by oral administration of total bovine bile (daily oral gavage of $70 \mathrm{mg} / \mathrm{kg}$ of body weight) or PBS from 4 weeks p.i. until the end of the experiment. Shown is the percentage of fecal G. lamblia antigen-positive animals over the course of the experiment ( $n=6$ to 7 per group from two litters). (H) Growth rate of $G$. lamblia in culture medium supplemented with $0.1 \%$ total bovine bile or $0.1 \%$ total murine bile after 48 hours ( $n=4$ per group). (I) Growth rate of $G$. lamblia in culture medium supplemented with taurocholic acid (TCA) or CA after 48 hours ( $n=4$ per group). (J) Comparative mass spectrometric analysis of bile acids in culture medium supplemented with bovine bile before (blue; $C T L$ ) and after (orange; G. lamblia) in vitro culture of $G$. lamblia for 48 hours (one of three independent experiments is presented). Graphs show means $\pm \mathrm{SD} ;{ }^{*} P<0.05,{ }^{* *} P<0.01,{ }^{* * *} P<0.001$, and ${ }^{* * *} P<0.0001$ by chi-square test (B), Mann-Whitney test ( $\mathrm{C}, \mathrm{D}$, and $\left.\mathrm{H}\right)$, Mantel-Cox test (F and G), or two-way ANOVA with Bonferroni post-test (I). All data are representative of two to three independent in vivo experiments. TCA, taurocholic acid; GCA, glycocholic acid; TDCA, taurodeoxycholic acid; TCDCA, taurochenoxycholic acid; GCDCA, glycochenodeoxycholic acid; GDCA, glycodeoxycholic acid; CA, cholic acid.

intestine $(P<0.05)$ (Fig. 5B). Although Staphylococcus was less abundant in infected adult animals $(P<0.01)$, it increased for the family Coriobacteriaceae $(P<0.01)$ and the genus Enterorhabdus $(P<0.01)$ therein (Fig. 5, C to E). Coriobacteriaceae very efficiently deconjugate bile acids (37). Mass spectrometric bile acid analysis revealed a reduction in all major taurine-conjugated bile acids including TCA $(P<0.05), \beta$-tauromuricholic acid $(\beta T M C A ; P<0.01)$ and $\omega$-tauromuricholic acid $(\omega \mathrm{TMCA} P<0.01)$, and taurourodeoxycholic 
A

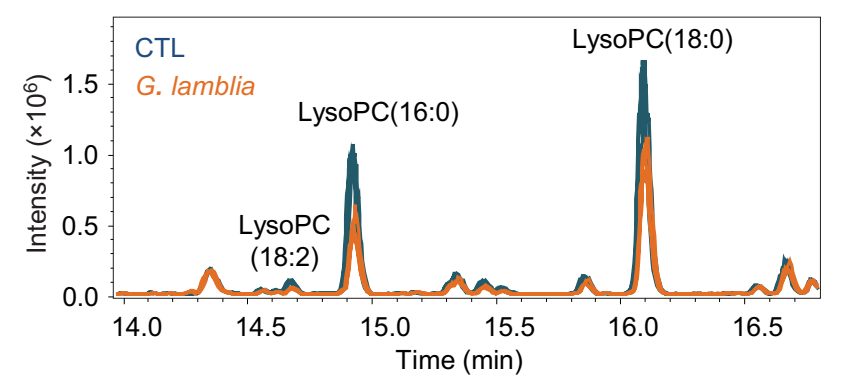

C

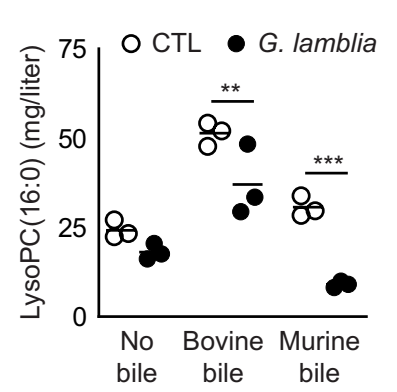

D

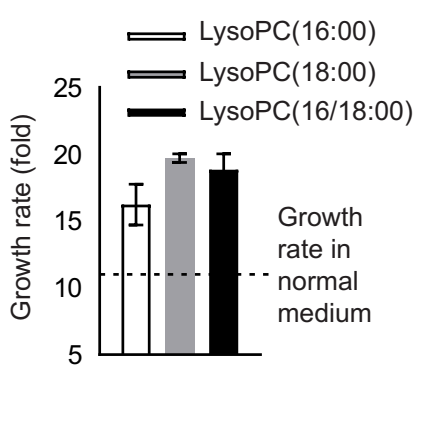

$\mathbf{F}$

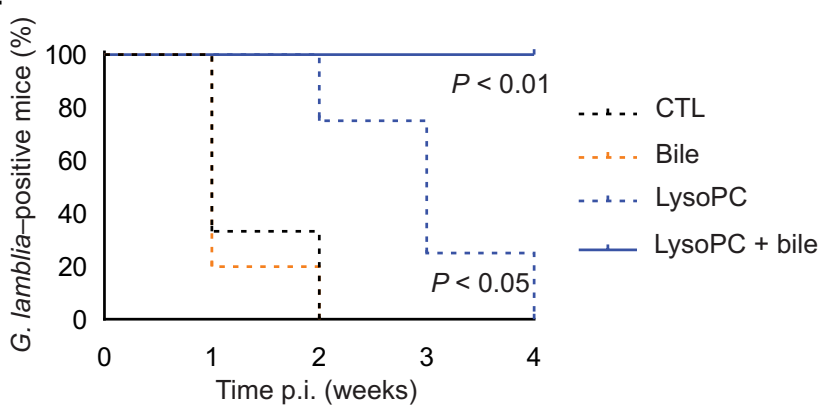

Fig. 4. Bile-derived LysoPC may be a metabolic substrate for G. Iamblia. (A) Comparative mass spectrometric analysis of the peak areas of LysoPC in culture medium supplemented with bovine bile before (blue; CTL) and after (orange; G. lamblia) in vitro culture of G. lamblia for 48 hours (one of three independent experiments is shown). (B and C) Quantitative analysis of LysoPC(16:0) (B) and LysoPC(18:0) (C) concentrations in culture medium (mg/liter) without bile (no bile) or supplemented with $0.1 \%$ bovine or murine bile before and after in vitro culture of G. lamblia for 48 hours ( $n=3$ per group). (D) The effect of LysoPC(16:0) (20 mg/liter), LysoPC(18:0) (20 mg/liter), or a mixture of LysoPC(16:0) and LysoPC(18:0) (20 mg/liter) in culture medium on G. lamblia growth after 48 hours of culture ( $n=4$ per group). (E) Quantitative RT-PCR for PLA $\mathrm{A}_{2}$ RNA expression in intestinal epithelial cells isolated from persistently G. lamblia-infected mice 4 weeks p.i. or healthy age-matched control animals after fasting for 12 hours. Three-day-old mice were infected with $2 \times 10^{5} \mathrm{G}$. lamblia trophozoites. Values were normalized to the expression of the housekeeping gene $h p r t$ ( $n=5$ to 6 per group from two litters). (F) Percentage of fecal G. lamblia antigen-positive mice after oral infection at 4 weeks with $1 \times 10^{7} \mathrm{G}$. lamblia trophozoites after 1 week of treatment with LysoPC with or without bovine bile or water (CTL). Treatment was LysoPC (100 g/liter) with or without total bovine bile (100 g/liter) in the drinking water, provided ad libitum from 1 week before infection until treatment end ( $n=7$ per group from two litters). (G) Percentage of fecal G. lamblia antigen-negative animals 4 weeks after weaning after oral infection of 3-day-old FVB Mdr2 ${ }^{+/+}$mice or FVB Mdr2 ${ }^{-/-}$mice ( $n=11$ to 15 per group from three litters). Graphs show means \pm SD measured by two-way ANOVA with Bonferroni post-test (B and $C$ ), Mann-Whitney test (E), or Mantel-Cox test $(\mathrm{F})$; ${ }^{*} P<0.05$, ${ }^{* *} P<0.01$, ${ }^{* *} P<0.001$, and ${ }^{* * * *} P<0.0001$. All data are representative of two to three independent in vivo experiments.

acid (TUDCA; $P<0.05$ ) in the small intestinal tissue of $G$. lambliainfected mice (Fig. 5F). Conversely, the corresponding unconjugated bile acids $\alpha$ MCA $(P<0.01)$ and $\beta$ MCA $(P<0.01)$ and chenodeoxycholic acid (CDCA; $P<0.05)$ were higher in the intestinal lumen and serum of infected adult animals (Figs. 5F and 3D). G. lamblia
B

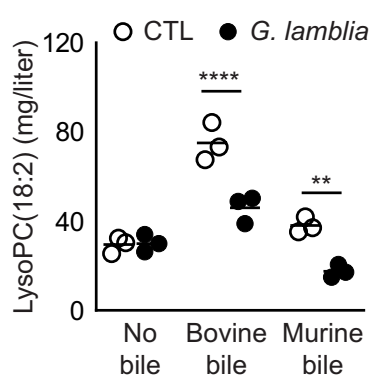

E

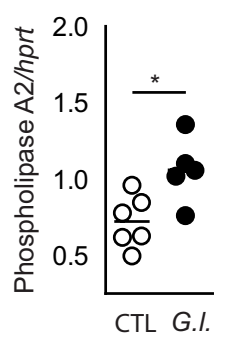

G

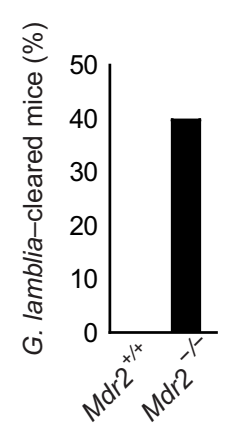

exerted no bile salt hydrolase activity, and free taurine did not support $G$. lamblia growth in vitro (fig. S5H). Thus, enhanced bile salt deconjugation most likely had no direct nutritional benefit for the parasite (30).

Instead, enhanced bile acid deconjugation in combination with the observed elevated enterohepatic cycle may have affected mouse host metabolism. CA and CDCA are farnesoid X receptor (FXR) agonists, whereas taurine-conjugated murocholic acids, the dominant bile acid type in the murine intestine, are potent FXR antagonists (38). The observed increase in CDCA in combination with a reduction in intestinal taurine-conjugated murocholic acids in G. lamblia-infected mice might, therefore, enhance FXR activation and, in turn, increase the expression of fibroblast growth factor 15 (FGF15). Intestinal epithelial FGF15 expression was higher in infected animals $(P<0.05)$ (Fig. 6A). FGF15 stimulates the FGF receptor 1 (FGFR1) in peripheral tissues and helps regulate metabolism, promote lipid oxidation and energy expenditure in adipocytes, and reduce body adipose tissue (39). Consistent with these functions, our metabolomic analysis revealed moderately increased concentrations of acylcarnitines in the serum of infected animals (Fig. 6B; fig. S6, A to C; and table S1). Acylcarnitines have also been found in the urine of G. lamblia-infected mice (20). Enhanced acylcarnitines have also been observed in healthy humans after fasting or exercise as a sign of excess lipolysis and mitochondrial overload $(40,41)$ and in children with environmental enteric dysfunction and increased intestinal permeability (42). Moreover, whole-body imaging and tissue dissection revealed decreased total adipose tissue $(P<0.05)$ (Fig. $6 \mathrm{C}$ and fig. S6, D and E), perigonadal adipose tissue $(P<0.01)$ (fig. S6, F and G), subcutaneous adipose tissue $(P<0.05)$ (Fig. 6, D to F), and brown adipose tissue $(P<0.05)$ (Fig. $6 \mathrm{G}$ and fig. S6, H and I) in G. lamblia-infected mice versus healthy control animals. G. lambliainfected animals also exhibited lower serum cholesterol concentrations $(P<0.05)$ (fig. S6J). Thus, secondary to altered gut microbiota composition and bacteria-induced bile salt deconjugation, metabolic dysregulation might cause the reduced weight gain and linear growth in persistently G. lambliainfected animals. Enhanced hepatic lipid synthesis to replace bile 
A
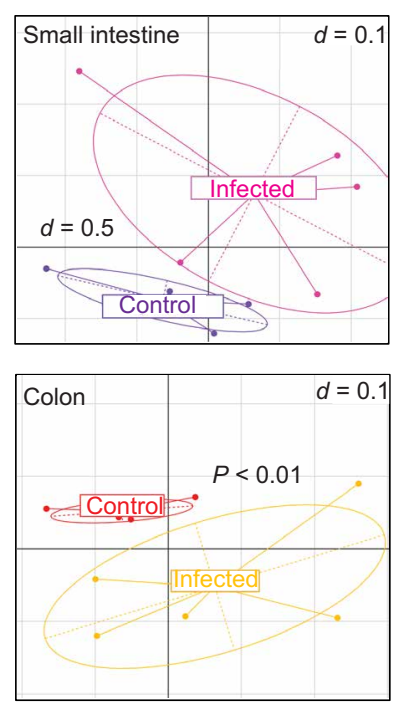

$\mathbf{F}$

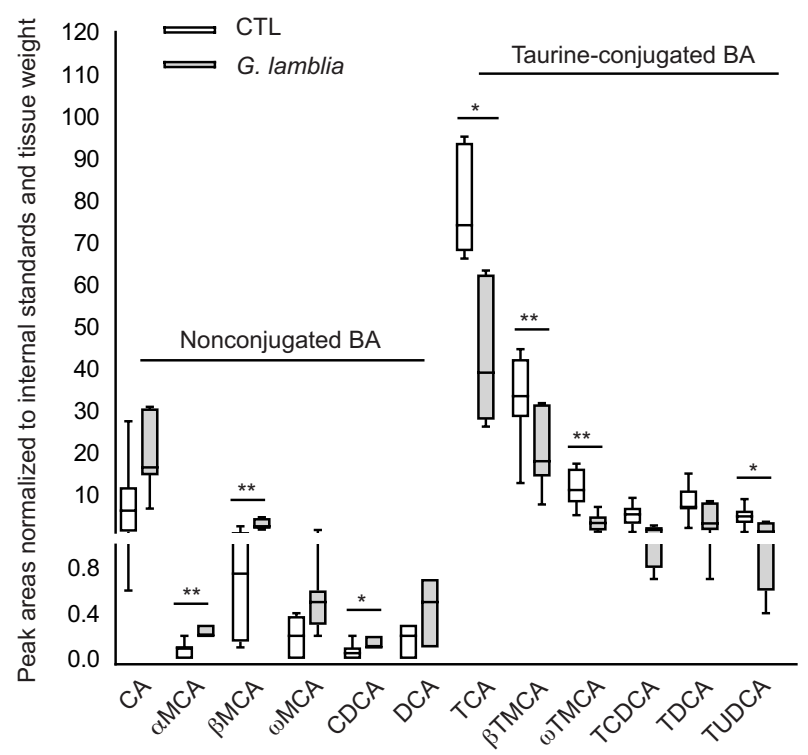

Fig. 5. Infection-induced changes in the enteric microbiota and bile salt hydrolase activity. (A) Principal coordinate analysis of the small intestinal (top) and colonic (bottom) microbiota composition of 4-week-old mice infected with G. lamblia as 3-day-old neonates compared to age-matched healthy control animals, as determined by $16 \mathrm{~S}$ ribosomal RNA gene amplicon sequencing ( $n=4$ to 5 per group from two litters). $d$, (dis)similarity distance of the generalized UniFrac defined by the distance between two grid lines. (B) Richness expressed as the number of operational taxonomic units (OTUs) detected in the small intestinal microbiota of 4-week-old persistently G. lamblia-infected (G.I.) mice or age-matched control animals ( $n=4$ to 5 per group from two litters). (C to E) Relative abundance of significantly different OTUs (phyla, families, and genera) in the colonic microbiota of 4-week-old persistently G. lamblia-infected mice (G.I.; $n=5$ from two litters) or agematched control animals ( $n=4$ to 5 per group from two litters). (F) Global mass spectrometric bile acid composition analysis of the small intestinal contents of adult mice chronically infected with $G$. lamblia or healthy control animals (CTL) is shown ( $n=7$ to 8 per group from two litters). Graphs show means \pm SD; ${ }^{*} P<0.05$ and ${ }^{* *} P<0.01$, by PERMANOVA (A) and Mann-Whitney test ( $B$ to F) (73). All data are representative of two to three independent in vivo experiments.
PCs consumed by G. lamblia, as illustrated by elevated hepatic concentrations of glycerophospholipids and PCs, might have further aggravated the observed metabolic phenotype (fig. S6C and table S2). Starvation clearly showed the severity of the G. lambliainduced global metabolic alteration in mouse hosts. After 16 hours of food deprivation, $G$. lamblia-infected animals were unable to maintain body temperature $(P<0.05)($ Fig. $6 \mathrm{H})$ and fell in a turgorlike state of reduced mobility (movies S1 and S2). This phenotype was fully reversible after administration of solid food (Fig. 6H). Thus, despite the restricted anatomical localization in the intestinal lumen, G. lamblia severely altered the mouse host's lipid metabolism, leading to reduced body weight gain and linear growth. Quantifying the human homolog FGF19 in serum samples obtained from children in an endemic area in Africa (43) revealed higher FGF19 concentrations in G. lamblia-positive children compared to G. lamblianegative controls $(P<0.05)$ (Fig. 6I).

\section{DISCUSSION}

In some areas of the world, G. lamblia is highly endemic, with a prevalence among children reaching well above $30 \%(8,10)$. Detection of this protozoan in this population is not linked to acute diarrheal disease $(5-8)$ but has been associated with failure to thrive $(44,45)$, reduced weight-for-age $(12,46,47)$, lower height-for-age (linear growth) $(12,17,46,48,49)$, and cognitive impairment (50). The neonatal murine infection model used here mimics the described associations in humans. Infection of neonatal mice led to chronic parasite carriage without the symptoms typically associated with acute G. lamblia infection. In addition, it has been reported that mouse neonatal infection did not alter either the anatomical crypt-villus architecture or enterocyte ultrastructure, induce infiltration by immune cells, impair epithelial barrier integrity, or reduce nutrient absorption (51). This is different from an adult mouse infection model, where T lymphocyte-induced epithelial damage was observed (52). Accordingly, this neonatal mouse model may help reveal why early exposure in humans predisposes to chronic carriage and secondary metabolic consequences leading to reduced body weight, growth deficits, and cognitive impairment $(7,10)$.

Infection of neonatal mice with $G$. lamblia trophozoites has previously been reported $(23,24)$. Although these studies noted initial parasite growth, they observed spontaneous clearance of the parasite 3 to 4 weeks after infection in contrast to the more than 20 weeks of parasite persistence in our study. The reason for the different outcome is not entirely clear; the use of different parasite strains (Portland 1, BRIS/83/HEPU/106 or BRIS/95/HEPU/2041 versus strain GS, clone H7 in our study), mouse strains and differences in their mucosal immune systems (CF-1 and Quackenbush Swiss mice versus C57BL/6 mice in our study), and environmental conditions in the animal facility might have contributed $(23,24,35)$. Chronic infection was observed in numerous experiments performed in two independent animal facilities over a period of 8 years.

Our results confirm that bile is a critical growth factor for G. lamblia in vivo (28). Given that G. lamblia has limited ability to synthesize lipids, bile might be a lipid source for membrane and organelle biosynthesis, energy production, and growth $(53,54)$. That G. lamblia can stimulate bile secretion accords with previous reports that observed increased spontaneous smooth muscle contractions in G. lamblia-infected mice and enhanced urinary excretion of bile acid constituents $(20,55)$. Constant cholecystokinin release 
Fig. 6. Metabolic consequences of persistent G. lamblia infection. (A) Quantitative RT-PCR for Fgf15 mRNA expression in the small intestine epithelial cells of persistently G. lamblia-infected mice (G.I.) compared to healthy age-matched control animals (CTL) after fasting for 12 hours (Fasting) or after fasting for 12 hours and access to food for $30 \mathrm{~min}$ (Food $+30 \mathrm{~min}$ ). Values were normalized to the expression of the housekeeping gene hprt ( $n=5$ to 10 per group from two to three litters). (B) Volcano plot of lipophilic metabolites, as measured by mass spectrometry, in serum of mice persistently infected with $G$. lamblia versus healthy age-matched control animals (CTL) ( $n=10$ to 11 per group from two to three litters). Black diamond, sugars; purple diamond, custom metabolomics indicator. The $\log _{2}$ fold change [Log(2)fc] between G. lamblia-infected mice and healthy control animals is shown. (C to G) Quantitative imaging of visceral and subcutaneous adipose tissue of control (CTL) and G. lambliainfected (G.I.) mice at 4 weeks p.i. is presented. (D) Three-dimensional (3D) volume renderings of segmented visceral (green) and subcutaneous (blue) adipose tissue and lung (pink) after $\mu \mathrm{CT}$ imaging (top) and 2D crosssectional $\mu \mathrm{CT}$ images in transversal planes of the abdomen (bottom). (C to G) Quantitative comparative analysis of (C) total adipose tissue, ( $D$ and E) subcutaneous adipose tissue, (D and F) visceral adipose tissue, and

(G) total brown adipose tissue (BAT) in relation to total body volume (\%) was performed ( $n=4$ to 5 per group from two litters). (H) Body temperature as determined by contactless infrared temperature measurement of $G$. lamblia-infected mice and healthy age-matched control animals (CTL) 1 day before starvation, after 16 hours of starvation, and 1 day later after free access to food ( $n=5$ to 7 per group from two litters). (I) Serum FGF19 concentrations determined by PCR in serum samples from children who were positive or negative for G. lamblia infection as part of an African cohort study on diarrheal diseases ( $n=23$ to 60 per group). Graphs show means $\pm S D ;{ }^{*} P<0.05$ by Mann-Whitney test $(A, C, E$ to $G$, and I) or two-way ANOVA with Sidak's post-test $(H)$. All data are representative of one to two independent in vivo experiments.

abolishes bile's trough and peak concentrations in the small intestine during fasting and after food intake, respectively, leading to more continuous bile constituent release into the proximal small intestine. Unexpectedly, we identified LysoPC as a growth factor for G. lamblia in vivo. Relatedly, PC is a predominant phospholipid class $(61.4 \%)$ in G. lamblia $(53,56)$ and urinary concentrations of choline breakdown metabolites in mice were higher after infection (20). G. lamblia can also internalize PC and LysoPC and convert them into various downstream lipids such as phosphatidylserine, phosphatidylethanolamine, and phosphatidylglycerol $(28,54)$. PC is a major constituent of bile and is rapidly converted into LysoPC by the small intestinal $\mathrm{PLA}_{2}$. G. lamblia infection raised epithelial expression of the host PLA 2 in a study using IL-17 $\mathrm{ra}^{-1-}$ mice, and this was shown to depend on interleukin-17 (IL-17) secretion (32). In addition, G. lamblia itself expresses two phospholipases that convert PC to LysoPC (57). PC also represents a major constituent of breast milk and might contribute to persistent infection upon challenge of neonatal animals (58). Besides LysoPC, bile acids promoted G. lamblia growth, although no bile acid consumption was detected. Because in humans, bile acids have been shown to be internalized by the parasite and thus might support the intake of lipids such as LysoPC $(27,28,30)$. Consistently, bile acids were shown to enhance the intake of lecithin, and oral bile acid (glycocholic acid) administration was shown to promote the luminal growth of the related parasite Giardia muris $(28,59)$. Moreover, bile salts protect the protozoan parasite from fatty acid-mediated killing in the small intestine (60). Increased bile secretion might thus serve both to provide lipid substrates for lipid remodeling and energy metabolism and to support parasitic lipid intake. In addition, elevated bile secretion may help protect G. lamblia-positive children against diarrheal disease caused by other enteropathogens (9-11). 
Alterations in the overall microbiota composition occur in the small and large intestines of adult $G$. lamblia-positive animals $(20,36)$. Because these changes are greater in adults than in acutely infected neonatal animals, enhanced bile acid secretion might explain the observed alteration of the gut microbiota. The higher abundance of bacteria from the genus Enterorhabdus, which are known to deconjugate bile salts, explains the observed increase in deconjugated and hydroxylated bile acids such as CDCA. The elevated bile acid deconjugation is also consistent with previously reported higher taurine concentrations in urine samples from G. lamblia-infected animals (20). Although changes in the gut microbiota composition have been associated with malnutrition and growth retardation (34), our gut microbiota transfer experiments to germ-free animals failed to provide evidence that the G. lamblia infection-induced alterations of the gut microbiota per se were sufficient to cause reduced body weight gain. However, one should keep in mind that inefficient transfer of specific fastidious or extremely sensitive taxa or neonatal age-restricted effects of the gut microbiota may limit the informative value of this experimental approach. Thus, the parasite-induced increased bile secretion and accelerated enterohepatic cycle in combination with gut microbiota alterations with elevated bile salt hydrolase activity might lead to reduced weight gain. The increased concentrations of unconjugated bile acids might additionally explain the moderately elevated intestinal fluid and fecal humidity in infected adult animals, consistent with previous reports on the bile acids' effect on fluid secretion (61).

The parasite-induced alteration of the host's bile physiology explains the observed metabolic phenotype in our study (fig. S8). By consuming LysoPC, G. lamblia withdraws energy-rich substrates from the host's metabolism. Accordingly, infected animals had increased PC concentrations in liver tissue, most probably because of the organism's attempt to refill the biliary PC pool. Enhanced concentrations of the FXR agonist CDCA and lower concentrations of the FXR antagonist $\beta$ TMCA enhanced FXR stimulation and epithelial FGF15 expression, thereby raising energy expenditure and diminishing adipose tissue in infected animals $(38,39,62)$. In addition to its role as a hepatic feedback signal for bile acid synthesis and release, FGF15 stimulates the FGFR1 in peripheral adipose tissue (63). FGF15 overexpression has been shown to increase energy expenditure and decrease adiposity in vivo $(39,64)$. Consistent with these observations, elevated FGF15 in infected animals was associated with globally reduced adipose body tissue. Further studies, however, are needed to establish a causative role of FGF15 for the observed reduction in the adipose tissue mass. The loss of adipose tissue rendered the animals unable to maintain energy homeostasis during starvation, as illustrated by reduced mobility and lowered body temperature under food restriction. Infection-induced energy utilization inefficiency aligns with a recent study that showed G. lamblia-infected animals experiencing protein deficiency had elevated $\beta$-oxidation metabolites in urine and reduced body weight (20). With elevated serum acylcarnitines and signs of increased fatty acid $B$-oxidation, the metabolic profile in G. lamblia-infected animals also reveals similarities with the metabolism of children with environmental enteric dysfunction, a widespread condition of children in developing countries and an accepted causative factor for impaired linear growth (42). A similar mechanism might thus be responsible for reduced body weight gain and linear growth reported in G. lamblia-infected human infants in endemic areas. G. lamblia- positive children had higher concentrations of the human FGF15 homolog, FGF19.

Although our study identified mechanisms in our animal model that may have contributed to reduced growth and body weight gain in children in endemic areas, much work remains to be done. For example, the mechanisms that render neonate mice susceptible to chronic parasite carriage and the role of the developing mucosal innate and adaptive immune system remain largely unresolved. In addition, how G. lamblia induces epithelial cholecystokinin secretion, which factors alter the enteric microbiota composition, and whether and to what extent enhanced FGF15/FGFR1 signaling contributes to the observed metabolic dysregulation and reduced growth require further work. Moreover, future prospective longitudinal studies are needed to analyze disease-associated changes such as altered bile acid and lipid metabolism as well as enteric microbiota composition in human infants in endemic areas and to confirm the G. lamblia infection-induced elevation of FGF19 as a causative factor for reduced body weight gain and linear growth. These studies should include additional cofactors such as nutritional status, dietary factors, and infections with other enteropathogens.

Together, our data suggest that neonatal G. lamblia infection of mice may mirror clinical features of infant G. lamblia infection in endemic areas, namely, delayed growth and curtailed body weight gain in the absence of intestinal inflammation and diarrhea. Our results illustrate the details of host-parasite interactions in a neonatal mouse model of infant $G$. lamblia infection and provide a plausible mechanistic explanation for altered lipid metabolism and growth retardation in persistently infected children.

\section{MATERIALS AND METHODS Study design}

The primary objective of this study was to use infection of neonatal mice with the protozoan parasite G. lamblia to characterize agedependent consequences of G. lamblia infection and to identify potential underlying mechanisms. Using in vitro culture assays and in vivo infection, we analyzed how persistent luminal G. lamblia infection dysregulated the host's bile acid homeostasis, enteric microbiota, and lipid metabolism, leading to impaired growth and reduced weight gain. All mouse litters ( $7 \pm 2$ pups per litter) or adult mice used in our experiments were randomized for treatment and optimized for sample size and sex matching. Except for the analysis of human sera and the whole-body imaging of mice, all experiments were repeated at least twice and results were pooled for analysis. All experiments were performed on at least two litters. For each experiment, the numbers of mice and experimental replicates are indicated in the figure legends. Samples were not excluded from analysis, and outliers are visible on the graphs. Investigators were not blinded during the experiments.

All animal experiments were performed in compliance with the German animal protection law (TierSchG) and approved by the local animal welfare committees, namely, the Niedersächsisches Landesamt für Verbraucherschutz und Lebensmittelsicherheit Oldenburg, Germany (33.12.42502-04-14/1344) and the Landesamt für Natur, Umwelt und Verbraucherschutz, North Rhine Westfalia (84-02.04.2015.A063 and 84-02.04.2016.A207). C57BL/6J wild-type (WT), FVB WT, and FVB Mdr2 ${ }^{-/-}$mice were bred locally and held under specific pathogen-free or germ-free conditions at the Institute of Laboratory Animal Science at RWTH Aachen University 
Hospital. Germ-free animals were provided by the animal facility at Hannover Medical School. The day of birth was considered day 1, i.e., animals infected at day 3 were about 48 hours old and verified to have ingested breast milk (milk spot). The human serum samples were derived from a previously published pediatric hospital-based cohort study on the epidemiology of malaria coinfections in Ghanaian children (43). This study was approved by the Ärztekammer Hamburg (no. PV4592) and the Committee on Human Research, Publications and Ethics, School of Medical Science, Kwame Nkrumah University of Science and Technology, Kumasi, Ghana (no. CHRPE/ AP/427/13).

\section{In vitro G. Iamblia culture}

G. lamblia ATCC 5058 (assemblage B, strain GS, clone H7) was used for all experiments in this study. Assemblage B strains account for the majority of human cases. G. lamblia medium was prepared by adding trypticase peptone (20 g; BD, no. 211921), yeast extract (10 g; Merck, no. WM983953), D(+) glucose (10 g; Sigma-Aldrich, no. G7528), $\mathrm{NaCl}$ ( 2 g; Sigma-Aldrich, no. S5886), $\mathrm{K}_{2} \mathrm{HPO}_{4}(1 \mathrm{~g}$; Sigma-Aldrich, no. $\mathrm{P} 2222), \mathrm{KH}_{2} \mathrm{PO}_{4}$ (0.6 g; Sigma-Aldrich, no. P5655), L-cysteine (2 g; Serva, no. 17769), L(+) ascorbic acid (0.2 g; Sigma-Aldrich, no. 33034), ammonium citrate (22.8 mg; Roth, no. CN77.1), bovine total bile (0.5 g; Sigma-Aldrich, no. B8381), ampicillin ( $50 \mu \mathrm{g} / \mathrm{ml}$; Roth, no. K029.2), and kanamycin $(100 \mu \mathrm{g} / \mathrm{ml}$; Roth, no. T832.1) to $900 \mathrm{ml}$ of distilled water and $100 \mathrm{ml}$ of heat-inactivated bovine serum (PAN-Biotech). The $\mathrm{pH}$ was adjusted to 7.0 to 7.1 , and the medium was sterile filtered using a $0.22-\mu \mathrm{m}$ vacuum filter (Pall). Culture flasks were kept at $37^{\circ} \mathrm{C}$ under anaerobic conditions using an anaerobic atmosphere generation bag and airtight container (BioMérieux). G. lamblia was split upon confluency (i.e., every 2 to 3 days) at 1:10. To allow detachment and harvest trophozoites for further use, culture medium was replaced with $5 \mathrm{ml}$ of cold sterile Dulbecco's phosphate-buffered saline (PBS) solution without $\mathrm{Ca}^{2+}$ and $\mathrm{Mg}^{2+}$ (Merck Millipore Biochrom) and incubated on ice for $10 \mathrm{~min}$. The trophozoite number was determined in a counting chamber by microscopy, and the suspension was adjusted by centrifugation at $2000 \mathrm{rpm}$ for $10 \mathrm{~min}$ at $4^{\circ} \mathrm{C}$ and resuspension to $10^{7}$ or $10^{8}$ trophozoites $/ \mathrm{ml}$ for the infection of neonates or adult mice, respectively.

\section{In vitro G. Iamblia experiments}

For in vitro growth experiments, G. lamblia trophozoites were seeded at a density of $10^{5}$ trophozoites per well in 12 -well plates. The number of viable parasites was determined after 48 hours of culture at $37^{\circ} \mathrm{C}$ under anaerobic conditions by detachment and counting as described above. The culture medium was supplemented with bovine bile at a concentration of 0 to $5 \%$ (Sigma-Aldrich, no. B8381), mouse bile at a concentration of $0.1 \%$ (collected by gall bladder puncture of healthy adult C57BL/6 mice), TCA at a concentration of 0 to $2.5 \mathrm{mM}$ (Sigma-Aldrich, no. T4009), CA (Sigma-Aldrich, no. C1129), taurine (Sigma-Aldrich, no. T0625), or LysoPC C16:0 and/or C18:0 (Avanti, nos. 17364168 and 19420576) at a concentration of 10 or $20 \mathrm{mg} /$ liter.

\section{In vivo G. Iamblia infection experiments}

All animals were derived from the same in-house breeding and bred in the same room and under the same conditions (hygiene, food, water, and bedding). Control and infection experiments were performed in parallel, and litters were randomly assigned to the different experimental groups. Three-, 14-, 21-day-old neonate and infant C57BL/6J mice were infected with $2 \times 10^{5} \mathrm{G}$. lamblia trophozoites in $20 \mu \mathrm{l}$ of PBS by gastric gavage. Adult (4 to 8 weeks old) conventionally raised $\mathrm{C} 57 \mathrm{BL} / 6, \mathrm{FVB} \mathrm{WT}$, or $\mathrm{FVB} \mathrm{Mdr}^{-/-}$mice were infected with $1 \times 10^{7} \mathrm{G}$. lamblia trophozoites in $100 \mu \mathrm{l}$ of PBS by gastric gavage. Control animals were gavaged by PBS only (sham gavage). FVB WT and FVB Mdr2 $2^{-l-}$ mice were bred in the same room, but littermates from heterozygous breeding were not used, and the enteric microbiota was not determined. Body weight and food/water intake were monitored, and fresh fecal samples were collected weekly to detect $G$. lamblia antigen by enzyme-linked immunosorbent assay (ELISA) (IBL International). Intestinal and liver tissue and serum/plasma were obtained for quantitative PCR, histology, electron microscopy, primary intestinal epithelial cell isolation, flow cytometry, and determining metabolites and viable counts at the indicated time points after infection. To determine viable organ counts, animals were starved for 4 hours, at which point the intestine was cut into six parts, longitudinally opened, and incubated in cold PBS for 2 to 3 hours on ice. The tissue was repeatedly rinsed, and the viable trophozoite number was determined in a counting chamber by microscopy. Epithelial barrier integrity was determined by oral gavage-administered fluorescein isothiocyanate (FITC)-dextran ( $4 \mathrm{kDa}$; TdB Consultancy) at a concentration of $750 \mathrm{mg} / \mathrm{kg}$ body weight. After 4 hours, the FITC-dextran concentration in plasma was assessed using a SpectraMax i3 at an excitation of $492 \mathrm{~nm}$ and an emission of $518 \mathrm{~nm}$ in combination with a serially diluted FITC-dextran standard. Results were expressed as $\mu \mathrm{g} / \mathrm{ml}$ of plasma. To measure tissue/fecal water content, duodenum, jejunum, and ileum, colon and feces from G. lamblia-infected and age-matched control animals were collected. Luminal content of the intestinal tissue or feces was weighed before and after the material was dried at $55^{\circ} \mathrm{C}$ for 48 hours. The weight difference corresponded to the water content in the gut lumen or feces and was expressed as percent of the total organ/fecal weight. To determine intestinal transit time, ground charcoal pieces (Sigma-Aldrich) were orally administered by gavage in $100 \mu \mathrm{l}$ (5\% charcoal and 10\% gum Arabica in PBS), and the distance that the charcoal had migrated through the small intestine was measured after 10 or $30 \mathrm{~min}$. For cholestyramine treatment, 8-week-old mice remained untreated or received cholestyramine $(500 \mu \mathrm{g} / \mathrm{g}$ of body weight per day) by oral gavage. After 2 weeks of treatment, mice were infected with $10^{7} \mathrm{G}$. lamblia trophozoites in $100 \mu \mathrm{l}$ of PBS by oral gavage. Body weight was monitored, and weekly fresh fecal samples were tested by ELISA for the presence of G. lamblia antigen. For oral bile administration, adult 6-week-old persistently G. lamblia-positive animals infected at the age of 3 days with $2 \times 10^{5}$ trophozoites were left untreated or treated daily by oral gavage with total bile $(70 \mu \mathrm{g} / \mathrm{g}$ of body weight). Body weight was monitored, and fresh fecal samples were collected weekly to be tested by ELISA for the presence of $G$. lamblia antigen. For oral LysoPC treatment, 26-day-old mice were left untreated, treated daily with LysoPC [(16:0)/(18:0) at 1:1 ratio], treated daily with bile only, or treated daily with bile and LysoPC $[(16: 0) /(18: 0)$ at $1: 1$ ratio] in drinking water [LysoPC $(16: 0)$ and (18:0) each at $1 \mathrm{~g} /$ liter, bovine bile if added at $1 \mathrm{~g} /$ liter]. At the age of 28 days (i.e., 2 days after the first LysoPC treatment), the animals were infected with $10^{7} \mathrm{G}$. lamblia trophozoites in $100 \mu \mathrm{l}$ of PBS by oral gavage. Body weight and food/water consumption were monitored, and fresh weekly fecal samples were tested by ELISA for the presence of G. lamblia antigen. Two different approaches were applied to evaluate the altered enteric microbiota's role in decreased weight gain in G. lamblia-infected animals. First, large intestinal 
content obtained from either 4-week-old mice infected at the age of 3 days or healthy age-matched animals was transferred to 8-weekold germ-free mice. Second, large intestinal content obtained from mice that were infected as 3-day-old neonates and had spontaneously cleared the infection after $>25$ weeks and agematched healthy animals was transferred to 8-week-old germ-free mice. For both approaches, body weight and food/water consumption were monitored and fresh fecal samples were collected weekly and tested by ELISA for the presence of G. lamblia antigen. Thereby, the only transient (first week after transfer) presence of G. lamblia in recipient animals after transfer of microbiota from G. lamblia-infected animals (approach 1) and the absence of G. lamblia antigen in recipient animals after transfer of microbiota from cleared animals (approach 2 ) were confirmed. These results are consistent with our observation that adult germ-free mice similar to adult conventional mice clear G. lamblia about 1 to 2 weeks after exposure (fig. S7). Parasite clearance might be specific for our model because other studies reported an elevated susceptibility of germ-free animals to G. lamblia infection $(65,66)$. To analyze $G$. lamblia-infected mice under starvation conditions, 4-week-old mice infected at the age of 3 days or healthy aged-matched control mice were starved for 12 hours (drinking water ad libitum). Half of the animals were sacrificed to obtain organs; the others were given food ad libitum for $30 \mathrm{~min}$ before sacrifice. Perigonal and brown adipose tissue were collected and weighed after cervical dislocation.

\section{Analyzing human serum samples}

Serum samples from $23 \mathrm{G}$. lamblia-positive and $60 \mathrm{G}$. lamblia-negative children, as determined by PCR from fecal samples, were obtained from the previously published study cohort (43), stored at $-80^{\circ}$, and analyzed by ELISA for FGF19 concentration (DF1900, R\&D Systems).

\section{Lipid analysis in culture medium, liver, and intestinal tissue}

To analyze lipid metabolites in culture medium, medium supernatants were centrifuged at $21,000 \mathrm{~g}$ for $5 \mathrm{~min}$ at $4^{\circ} \mathrm{C}$ to remove particles and debris. Fifty microliters were used for separating bile acids and matching. To quantify LysoPC quantification, centrifuged supernatants were diluted 1:2002 in cold methanol to fit peak areas into established calibration curves. Liver and small intestine content (about $10 \mathrm{mg}$ ) were weighed into sterile ceramic bead tubes (NucleoSpin Bead Tubes, Macherey-Nagel) and extracted with $1 \mathrm{ml}$ of chilled methanol, containing $0.2 \mathrm{ppm}$ (parts per million) of deuterium-labeled bile acid mix (d5-TCA, d4-glycodeoxycholic acid, d4-CA, and d4-deoxycholic acid; table S3) as internal standards. Homogenizing and extracting samples were performed with Precellys Evolution homogenizer (Bertin Corp.; $4500 \mathrm{rpm}$; $40 \times 3 \mathrm{~s}$; pause time, $2 \mathrm{~s}$ ). Samples were centrifuged at $21,000 \mathrm{~g}$ for $10 \mathrm{~min}$ at $4^{\circ} \mathrm{C}$. Supernatants were transferred into sterile microcentrifuge tubes and stored at $-80^{\circ} \mathrm{C}$ before analysis. LC-MS (liquid chromatographymass spectrometry)-grade methanol, acetonitrile, isopropanol, and ammonium acetate were obtained from Fluka (LC-MS CHROMASOLV). Glacial acetic acid was purchased from Biosolve (ULC/MS). Ultrapure water (milliQH2O) was derived from a Milli-Q apparatus (Milli-Q Integral Water Purification System). 1-Palmitoyl-sn-glycero-3phosphocholine [LysoPC(16:0)] and 1-stearoyl-sn-glycero-3phosphocholine [LysoPC(18:0)] were purchased from Sigma-Aldrich. Both were dissolved in pure methanol to a stock solution of $1 \mathrm{mg} / \mathrm{ml}$ (1000 ppm). LysoPCs were mixed, and an equidistant five-point calibration curve of 0.001 to $0.005 \mathrm{ppm}$ was prepared to quantify
LysoPCs in supernatants. To analyze bile acid, 34 and 4 deuteriumlabeled bile acids (table S3) were used for identification and normalization, respectively. Stock bile acid solutions were prepared $(1 \mathrm{mg} / \mathrm{ml})$ in pure methanol and stored in $4^{\circ} \mathrm{C}$ until analyses. A mixture combining all bile acids $(0.2 \mathrm{ppm})$ was analyzed simultaneously. Analyses of bile acids, LysoPCs, and extracted samples were performed with ultrahigh-performance liquid chromatography (ACQUITY UPLC, Waters) coupled to MS, as described previously (67). Moreover, bile acids were measured in negative and LysoPCs in positive electrospray ionization mode. Bile acids were acquired in full-scan mode (50 to $1000 \mathrm{~m} / z$ ), whereas LysoPCs were acquired in multiple reaction-monitoring mode with a $5-\mathrm{Da}$ isolation window and $0.75-\mathrm{V}$ fragmentation amplitude. Isolation masses of parent ions, major fragments, and retention times were as follows: LysoPC(16:0): $[\mathrm{M}+\mathrm{H}]+: 464.60->478.4 / 14$ to $15 \mathrm{~min}$ and $[\mathrm{M}+\mathrm{H}]+: 524.40-$ $>506.4 / 15$ to $16 \mathrm{~min}$. For data processing, targeted peak picking of bile acids was performed in Genedata Expressionist [mass values (M-H-) and retention time were measured in min, as shown in table S3]. Peak areas were normalized to internal standards and sample weight (in mg). Calibration of LysoPCs quantities was performed in QuantAnalysis (Bruker Daltonics, Bremen, Germany).

\section{Lipid analysis in serum samples}

The Bile Acids Kit (Biocrates Life Sciences AG) was used as described in the manufacturer's instructions. Metabolites were extracted from liver samples by adding $\mathrm{H}_{2} \mathrm{O} /$ acetonitrile $(1: 1, \mathrm{v} / \mathrm{v})$ per $\mathrm{mg}$ of sample, followed by homogenization with a tissue slicer for $10 \mathrm{~min}$ at $30 \mathrm{~Hz}$ with four steel beads. Samples were centrifuged at $1400 \mathrm{~g}$ for $2 \mathrm{~min}$, and the supernatant was analyzed. The targeted analysis was performed by adding $10 \mu \mathrm{l}$ of extracted serum samples to the AbsoluteIDQ p180 Kit (Biocrates Life Science AG), following the vendor's instructions (68).

\section{Bomb calorimetry}

To analyze intestinal energy absorption, total fecal material was collected over a defined time period ( 7 days), during which food intake and body weight were monitored. The dried sample material was homogenized, pressed to a tablet, weighed, and analyzed in duplicate by bomb calorimetry using a GMC bomb calorimeter (IKA C7000), following the manufacturer's instructions.

\section{Quantification of G. lamblia by PCR}

Freshly collected fecal samples and standards with $10^{6}$ to $10^{2}$ G. lamblia trophozoites (genome copies) per ml obtained by overnight culture and verified by counting under the binocular were stored at $-80^{\circ} \mathrm{C}$. DNA isolation was performed using the QIAamp DNA Stool Kit (QIAGEN, reference 51504) with one modification (step 3, temperature of $95^{\circ} \mathrm{C}$ instead of $70^{\circ} \mathrm{C}$ ). The DNA concentration was determined on a NanoDrop 1000 spectrophotometer (Thermo Fisher Scientific). HotStarTaq Master Mix (10 $\mu$ l; QIAGEN), $0.2 \mu \mathrm{l}$ of the forward primer Giardia-80F 5'-GACGGCTCAGGACAACGGTT-3' (69), $0.2 \mu \mathrm{l}$ of the reverse primer Giardia-127R 5'-TTGCCAGCGGTGTCCG-3' (69), $0.2 \mu$ l of the double-labeled probe Giardia-105T FAM-5'-CCCGCGGCGGTCCCTGCTAG-3'-black hole quencher 1 (69), $3 \mu \mathrm{l}$ of $\mathrm{MgCl}_{2}$ (from $25 \mathrm{mM}$ substrate; Thermo Fisher Scientific), and $4,4 \mu \mathrm{l}$ of RNA/DNA-free $\mathrm{H}_{2} \mathrm{O}$ were mixed. Eighteen microliters of the mix was added to $2 \mu \mathrm{l}$ of DNA. The plate was centrifuged at $200 \mathrm{~g}$ at $4^{\circ} \mathrm{C}$ for $2 \mathrm{~min}$ and treated in the thermocycler for $15 \mathrm{~min}$ at $95^{\circ} \mathrm{C}$, followed by 40 cycles of $15 \mathrm{~s}$ at $95^{\circ} \mathrm{C}, 30 \mathrm{~s}$ 
at $60^{\circ} \mathrm{C}$, and $30 \mathrm{~s}$ at $72^{\circ} \mathrm{C}$. Fluorescence emitted at $490 \mathrm{~nm}$ was recorded. The data were analyzed using Bio-Rad CFX Manager software. The results were normalized per gram of feces for each sample.

\section{Electron microscopy}

Tissues were fixed overnight by immersion in $2 \%(\mathrm{w} / \mathrm{v})$ glutaraldehyde (Polysciences Inc.) in $130 \mathrm{mM}$ cacodylate buffer at $\mathrm{pH} 7.4$ supplemented with $2 \mathrm{mM} \mathrm{CaCl} 2$ and $10 \mathrm{mM} \mathrm{MgCl}_{2}$. The specimens were incubated for 1 hour with $1 \%(\mathrm{w} / \mathrm{v}) \mathrm{OsO}_{4}$ (Polysciences Inc.) in $165 \mathrm{mM}$ cacodylate buffer containing $1.5 \%(\mathrm{w} / \mathrm{v}) \mathrm{K}_{3}\left[\mathrm{Fe}(\mathrm{CH})_{6}\right]$, followed by $0.5 \%(\mathrm{w} / \mathrm{v})$ uranyl acetate (Agar Scientific) in 50\% (v/v) ethanol overnight. The samples were embedded in Epon [29.19 $\mathrm{g}$ of Epon $812,12.66 \mathrm{~g}$ of Dodecenylsuccinic anhydride (DDSA), $16.58 \mathrm{~g}$ of Methylnadicanhydride (MNA), and $0.75 \mathrm{ml}$ of 2,4,6-Tris(dimethylaminomethyl)phenol (DMP30); Serva Electrophoresis GmbH]. After Epon hardening at $60^{\circ} \mathrm{C}$, ultrathin sections of $50-\mathrm{nm}$ thickness were cut and further contrasted with lead citrate and uranyl acetate. Images were taken with Morgani or Tecnai G2 T20 electron microscopes (FEI) and further processed using ImageJ (version 1.50f).

\section{Flow cytometric analysis}

To isolate immune cells, the intestine was cut longitudinally and incubated for $2 \times 15 \mathrm{~min}$ in $2 \mathrm{mM}$ EDTA/Hanks' balanced salt solution at $37^{\circ} \mathrm{C}$ to remove the epithelium. The lamina propria was digested in Liberase/deoxyribonuclease ( $30 \mu \mathrm{g} / \mathrm{ml}$; Roche) for $45 \mathrm{~min}$ at $37^{\circ} \mathrm{C}$ and filtered through a $100-\mu \mathrm{m}$ nylon cell strainer to obtain a single-cell suspension. Flow cytometric analysis used the following gating strategy and antibodies (all purchased from BioLegend). Initially, all samples were pregated on $\mathrm{CD}^{+} 5^{+}$(CD45-BV510, 30-F11) $7 \mathrm{AAD}^{-}$(PerCP/7AAD) singlets. Macrophages were subsequently identified by MHCII $^{\text {hi }}$ (MHCII-AF488, M5/115.14.2) and CD11c ${ }^{+}$ (CD11c-PECy7, N418), as well as $\mathrm{CD}^{+}{ }^{+}$(CD64-APC, X54-5/7.1) and $\mathrm{CD}_{11 \mathrm{~b}}{ }^{+}$(CD11b-APC, M1/70); monocytes were subsequently identified by Ly6C ${ }^{\text {hi }}$ (Ly6C-PerCPCy5.5, HK1.4) and Ly6G ${ }^{-}$(Ly6G-PE, 1A8). Polymorphonuclear cells were subsequently identified by Ly6 $\mathrm{C}^{\text {int }}$ and $\mathrm{Ly}_{6 \mathrm{G}}{ }^{+}$, and mast cells were subsequently identified by $\mathrm{MHCII}^{+}$, as well as FceR ${ }^{+}$(FceR-PE, MAR-1) and c-kit ${ }^{+}$(ckit-APC, 2B8). Data were acquired with a BD FACSCanto II and analyzed with FlowJo X.

\section{Primary intestinal epithelial cell isolation and gene expression analysis}

Isolation of primary intestinal epithelial cells was performed as recently described (70). For gene expression analysis, total RNA was extracted from isolated intestinal epithelial cells or liver tissue using TRIzol (Invitrogen), and the RNA concentration was determined on a NanoDrop 1000 spectrophotometer (Thermo Fisher Scientific). First-strand cDNA was synthesized from $5 \mu \mathrm{g}$ of total RNA using Oligo-dT primers, RevertAid reverse transcriptase, and RiboLock ribonuclease inhibitor (Thermo Fisher Scientific). Reverse transcription PCR (RT-PCR) was performed using the TaqMan technology with an absolute QPCR (quantitative real-time fluorescence PCR) ROX mix (Thermo Fisher Scientific); sample cDNA; and the TaqMan probes Hprt (Mm00446968-m1), cck (Mm00446170-m1), phospholipase A2 (Mm 00448160-m1), fgf15 (Mm00433278-m1), cyp7a (Mm00484150-m1), cyp7b (Mm 00484157-m1), cyp27a (Mm00470430-m1), and baat (Mm00476075-m1) (Life Technologies). Results were calculated by the $\Delta 2-\mathrm{CT}$ method. For data analysis, values were normalized to the hprt housekeeping gene and presented as fold induction over age-matched controls.

\section{Gut microbiota analysis}

For microbiota analysis, dams were co-housed for at least 5 weeks before conception and during pregnancy and birth. On the day of birth, dams with their litters were separated, and the neonates at 3 days after birth were either infected with G. lamblia in PBS or treated with PBS only. Samples for all groups of the microbiota analyses were taken from animals of least two litters per cages. Total small intestinal and colon tissues were collected at 1 and 4 weeks p.i., respectively. Total genomic DNA from snap-frozen intestinal tissues was isolated by repeated bead beating combined with chemical lysis and a column-based purification method, as described in detail elsewhere (71). Each batch of samples undergoing DNA isolation included one negative control consisting of PCR-grade water. Amplicon library generation and sequencing were performed according to previously published protocols $(72,73)$. A total of 15,426,330 V3-V4 reads were generated by sequencing. After trimming, quality filtering, removing potential chimeric reads, and demultiplexing then removing low abundant operational taxonomic units (OTUs), $12,912,927$ sequences belonging to 177 OTUs were retained for downstream analysis. Negative control samples were excluded from subsequent analysis. For the remaining samples, which were used to further data analysis, the number of sequences per sample ranged from 193,055 to 502,246 (median, 313,306). Data demultiplexing, length and quality filtering, read pairing, and read clustering into OTUs at $97 \%$ sequence identity were done via the online Integrated Microbial Next-Generation Sequencing platform (74) using default settings except for minimum and maximum amplicon length, which were set to 300 and 600 base pairs, respectively. Data normalization, diversity, taxonomical binning, and group comparisons were performed using the Rhea package (75). Alpha- (observed species, Chaol and Shannon index) and beta-diversity (generalized UniFrac) (76) estimates were computed using the R pipeline Rhea standard script and settings. Ordination of samples from different groups was based on generalized UniFrac, with (dis)similarities visualized by Non-metric distance scaling (NMDS). A permutational multivariate analysis of variance (PERMANOVA) using distance matrices (vegan::adonis) was performed to determine whether each group separation was significant, as a whole and in pairs. Alphadiversity parameters and the occurrence of bacterial genera, families, and phyla were first tested across all groups using the nonparametric Kruskal-Wallis test adjusted for multiple comparisons by the BenjaminiHochberg method. For this analysis, apart from the default settings, we used no cutoff for either relative or median abundance, and zeros were included in statistics. In case of significance $(P<0.05)$, pairwise group comparison (infected versus control) was performed using the Mann-Whitney test corrected for multiple testing, resulting in the indicated $P$ values. All taxa with significantly different large intestinal abundance according to the Kruskal-Wallis test are reported.

\section{Whole-body adipose tissue imaging}

For imaging-based adipose tissue quantification, sacrificed G. lambliainfected (4 weeks p.i.) and age-matched healthy control animals were placed into a preclinical x-ray micro-computed tomography $(\mu \mathrm{CT})$ scanner (MILabs B.V.) for a total-body $\mu \mathrm{CT}$ scan. $\mu \mathrm{CT}$ scans were performed using an $\mathrm{x}$-ray tube voltage of $65 \mathrm{kV}$ and power of $0.13 \mathrm{~mA}$. A full gantry rotation acquired 360 projections at an exposure time of $75 \mathrm{~ms}$ and an estimated dose of 35 milligray. For image analysis, all acquired three-dimensional CT images were reconstructed at an isotropic voxel size of $80 \mu \mathrm{m}$ using a Feldkamp-type 
algorithm (filtered back projection). The adipose tissue-containing anatomical regions, which appear hypointense in the $\mu \mathrm{CT}$, were segmented using an automated segmentation method that interactively corrected segmentation errors. For all analyses, we used Imalytics Preclinical software $(77,78)$. The volumetric adipose tissue percentage was computed as the ratio of total, subcutaneous, visceral, or brown adipose tissue volume to the total body volume.

\section{Statistical analysis}

Data analyses were performed with GraphPad Prism 7.0 software. Statistical analyses were performed for the intergroup variation of gut microbiota composition by PERMANOVA, for the analysis of positive fecal G. lamblia antigen testing over time (Kaplan-Meier curve) with the Mantel-Cox test, for comparisons between two groups with the Mann-Whitney $U$ test for nonparametrically distributed data and for multigroup comparisons with the two-way analysis of variance (ANOVA) with Sidak's or Bonferroni post hoc analysis. $P$ values are indicated as follows: ${ }^{* * *} P<0.0001$, ${ }^{* *} P<0.001$, ${ }^{*} P<0.01$, and ${ }^{*} P<0.05$.

\section{SUPPLEMENTARY MATERIALS}

stm.sciencemag.org/cgi/content/full/12/565/eaay7019/DC1

Fig. S1. Neonatal infection leads to persistent infection.

Fig. S2. Parasite persistence leads to impaired growth and weight gain.

Fig. S3. Enhanced bile secretion upon G. lamblia persistence.

Fig. S4. Bile-derived LysoPC as a metabolic substrate and persistence-promoting factor for G. Iamblia.

Fig. S5. Infection-induced changes of the enteric microbiota.

Fig. S6. Metabolic consequences of persistent G. lamblia infection.

Fig. S7. G. lamblia infection of adult germ-free animals.

Fig. S8. Potential mechanisms contributing to reduced postnatal body weight gain and linear growth.

Table S1. Metabolic profiling for acylcarnitines in serum of mice persistently infected with G. lamblia versus healthy age-matched control animals.

Table S2. Metabolic profiling for PCs in total liver tissue of mice persistently infected with G. lamblia versus healthy age-matched control animals.

Table S3. Bile acid standards for metabolically profiling bile acids.

Movie S1. Representative live imaging of a healthy 4-week-old mouse.

Movie S2. Representative live imaging of a mouse, infected at the age of 3 days with G. lamblia, at 4 weeks p.i.

Data file S1. Individual-level data for all figures.

View/request a protocol for this paper from Bio-protocol.

\section{REFERENCES AND NOTES}

1. S. A. Squire, U. Ryan, Cryptosporidium and Giardia in Africa: Current and future challenges. Parasit. Vectors 10, 195 (2017).

2. T. E. Nash, D. A. Herrington, G. A. Losonsky, M. M. Levine, Experimental human infections with Giardia lamblia. J. Infect. Dis. 156, 974-984 (1987).

3. E. A. Adam, J. S. Yoder, L. H. Gould, M. C. Hlavsa, J. W. Gargano, Giardiasis outbreaks in the United States, 1971-2011. Epidemiol. Infect. 144, 2790-2801 (2016).

4. M. J. Farthing, Giardiasis. Gastroenterol. Clin. North Am. 25, 493-515 (1996).

5. M. G. Hollm-Delgado, R. H. Gilman, C. Bern, L. Cabrera, C. R. Sterling, R. E. Black, W. Checkley, Lack of an adverse effect of Giardia intestinalis infection on the health of Peruvian children. Am. J. Epidemiol. 168, 647-655 (2008).

6. S. Centeno-Lima, V. Rosado-Marques, F. Ferreira, R. Rodrigues, B. Indeque, I. Camará, B. De Sousa, P. Aguiar, B. Nunes, P. Ferrinho, Giardia duodenalis and chronic malnutrition in children under five from a rural area of Guinea-Bissau. Acta Med. Port. 26, 721-724 (2013).

7. J. R. Donowitz, M. Alam, M. Kabir, J. Z. Ma, F. Nazib, J. A. Platts-Mills, L. A. Bartelt, R. Haque, W. A. Petri Jr., A prospective longitudinal cohort to investigate the effects of early life giardiasis on growth and all cause diarrhea. Clin. Infect. Dis. 63, 792-797 (2016).

8. K. Muhsen, M. M. Levine, A systematic review and meta-analysis of the association between Giardia lamblia and endemic pediatric diarrhea in developing countries. Clin. Infect. Dis. 55, S271-S293 (2012).

9. K. L. Kotloff, J. P. Nataro, W. C. Blackwelder, D. Nasrin, T. H. Farag, S. Panchalingam, Y. Wu, S. O. Sow, D. Sur, R. F. Breiman, A. S. G. Faruque, A. K. M. Zaidi, D. Saha, P. L. Alonso,
B. Tamboura, D. Sanogo, U. Onwuchekwa, B. Manna, T. Ramamurthy, S. Kanungo, J. B. Ochieng, R. Omore, J. O. Oundo, A. Hossain, S. K. Das, S. Ahmed, S. Qureshi, F. Quadri, R. A. Adegbola, M. Antonio, M. J. Hossain, A. Akinsola, I. Mandomando, T. Nhampossa, S. Acácio, K. Biswas, C. E. O'Reilly, E. D. Mintz, L. Y. Berkeley, K. Muhsen, H. Sommerfelt, R. M. Robins-Browne, M. M. Levine, Burden and aetiology of diarrhoeal disease in infants and young children in developing countries (the Global Enteric Multicenter Study, GEMS): A prospective, case-control study. Lancet 382, 209-222 (2013).

10. E. T. Rogawski, L. A. Bartelt, J. A. Platts-Mills, J. C. Seidman, A. Samie, A. Havt, S. Babji, D. R. Trigoso, S. Qureshi, S. Shakoor, R. Haque, E. Mduma, S. Bajracharya, S. M. A. Gaffar, A. A. M. Lima, G. Kang, M. N. Kosek, T. Ahmed, E. Svensen, C. Mason, Z. A. Bhutta, D. R. Lang, M. Gottlieb, R. L. Guerrant, E. R. Houpt, P. O. Bessong; MAL-ED Network Investigators, Determinants and impact of Giardia infection in the first 2 years of life in the MAL-ED birth cohort. J. Pediatric Infect. Dis. Soc. 6, 153-160 (2017).

11. J. Veenemans, T. Mank, M. Ottenhof, A. Baidjoe, E. V. Mbugi, A. Y. Demir, J. P. Wielders, H. F. Savelkoul, H. Verhoef, Protection against diarrhea associated with Giardia intestinalis is lost with multi-nutrient supplementation: A study in Tanzanian children. PLOS Negl. Trop. Dis. 5, e1158 (2011).

12. E. T. Rogawski, J. Liu, J. A. Platts-Mills, F. Kabir, P. Lertsethtakarn, M. Siguas, S. S. Khan, I. Praharaj, A. Murei, R. Nshama, B. Mujaga, A. Havt, I. A. Maciel, D. J. Operario, M. Taniuchi, J. Gratz, S. E. Stroup, J. H. Roberts, A. Kalam, F. Aziz, S. Qureshi, M. O. Islam, P. Sakpaisal, S. Silapong, P. P. Yori, R. Rajendiran, B. Benny, M. McGrath, J. C. Seidman, D. Lang, M. Gottlieb, R. L. Guerrant, A. A. M. Lima, J. P. Leite, A. Samie, P. O. Bessong, N. Page, L. Bodhidatta, C. Mason, S. Shrestha, I. Kiwelu, E. R. Mduma, N. T. Iqbal, Z. A. Bhutta, T. Ahmed, R. Haque, G. Kang, M. N. Kosek, E. R. Houpt; MAL-ED Network Investigators, Use of quantitative molecular diagnostic methods to investigate the effect of enteropathogen infections on linear growth in children in low-resource settings: Longitudinal analysis of results from the MAL-ED cohort study. Lancet Glob. Health 6, e1319-e1328 (2018).

13. R. Goto, C. G. Mascie-Taylor, P. G. Lunn, Impact of intestinal permeability, inflammation status and parasitic infections on infant growth faltering in rural Bangladesh. Br. J. Nutr. 101, 1509-1516 (2009).

14. J. A. Platts-Mills, S. Babji, L. Bodhidatta, J. Gratz, R. Haque, A. Havt, B. J. McCormick, M. McGrath, M. P. Olortegui, A. Samie, S. Shakoor, D. Mondal, I. F. Lima, D. Hariraju, B. B. Rayamajhi, S. Qureshi, F. Kabir, P. P. Yori, B. Mufamadi, C. Amour, J. D. Carreon, S. A. Richard, D. Lang, P. Bessong, E. Mduma, T. Ahmed, A. A. Lima, C. J. Mason, A. K. Zaidi, Z. A. Bhutta, M. Kosek, R. L. Guerrant, M. Gottlieb, M. Miller, G. Kang, E. R. Houpt; MAL-ED Network Investigators, Pathogen-specific burdens of community diarrhoea in developing countries: A multisite birth cohort study (MAL-ED). Lancet Glob. Health 3, e564-e575 (2015).

15. M. I. Sato, A. T. Galvani, J. A. Padula, A. C. Nardocci, M. de Souza Lauretto, M. T. Razzolini, E. M. Hachich, Assessing the infection risk of Giardia and Cryptosporidium in public drinking water delivered by surface water systems in Sao Paulo State, Brazil. Sci. Total Environ. 442, 389-396 (2013).

16. L. A. Bartelt, R. B. Sartor, Advances in understanding Giardia: Determinants and mechanisms of chronic sequelae. F1000Prime Rep. 7, 62 (2015).

17. M. C. Halliez, A. G. Buret, Extra-intestinal and long term consequences of Giardia duodenalis infections. World J. Gastroenterol. 19, 8974-8985 (2013).

18. E. Einarsson, S. Ma'ayeh, S. G. Svärd, An up-date on Giardia and giardiasis. Curr. Opin. Microbiol. 34, 47-52 (2016)

19. S. A. Richard, B. J. J. McCormick, L. E. Murray-Kolb, G. O. Lee, J. C. Seidman, M. Mahfuz, T. Ahmed, R. L. Guerrant, W. A. Petri, E. T. Rogawski, E. Houpt, G. Kang, E. Mduma, M. N. Kosek, A. A. M. Lima, S. K. Shrestha, R. K. Chandyo, Z. Bhutta, P. Bessong, L. E. Caulfield; MAL-ED Network Investigators, Enteric dysfunction and other factors associated with attained size at 5 years: MAL-ED birth cohort study findings. Am. J. Clin. Nutr. 110, 131-138 (2019).

20. L. A. Bartelt, D. T. Bolick, J. Mayneris-Perxachs, G. L. Kolling, G. L. Medlock, E. I. Zaenker, J. Donowitz, R. V. Thomas-Beckett, A. Rogala, I. M. Carroll, S. M. Singer, J. Papin, J. R. Swann, R. L. Guerrant, Cross-modulation of pathogen-specific pathways enhances malnutrition during enteric co-infection with Giardia lamblia and enteroaggregative Escherichia coli. PLOS Pathog. 13, e1006471 (2017).

21. L. A. Bartelt, J. Roche, G. Kolling, D. Bolick, F. Noronha, C. Naylor, P. Hoffman, C. Warren, S. Singer, R. Guerrant, Persistent G. lamblia impairs growth in a murine malnutrition model. J. Clin. Invest. 123, 2672-2684 (2013).

22. G. Shukla, R. K. Sidhu, Lactobacillus casei as a probiotic in malnourished Giardia lamblia-infected mice: A biochemical and histopathological study. Can. J. Microbiol. 57 127-135 (2011).

23. D. R. Hill, R. L. Guerrant, R. D. Pearson, E. L. Hewlett, Giardia lamblia infection of suckling mice. J. Infect. Dis. 147, 217-221 (1983).

24. A. L. Williamson, P. J. O'Donoghue, J. A. Upcroft, P. Upcroft, Immune and pathophysiological responses to different strains of Giardia duodenalis in neonatal mice. Int. J. Parasitol. 30, 129-136 (2000).

25. T.-L. Chen, S. Chen, H.-W. Wu, T.-C. Lee, Y.-Z. Lu, L.-L. Wu, Y.-N. Ni, C.-H. Sun, W.-H. Yu, A. G. Buret, L. C. Yu, Persistent gut barrier damage and commensal bacterial influx following eradication of Giardia infection in mice. Gut Pathog. 5, 26 (2013). 
26. E. Li, E. A. Tako, S. M. Singer, Complement activation by Giardia duodenalis parasites through the lectin pathway contributes to mast cell responses and parasite control. Infect. Immun. 84, 1092-1099 (2016).

27. D. Siddhartha, C. D. Schteingart, A. F. Hofmann, D. S. Reiner, S. B. Aley, F. D. Gillin, Giardia lamblia: Evidence for carrier-mediated uptake and release of conjugated bile acids. Exp. Parasitol. 87, 133-141 (1997).

28. M. J. Farthing, G. T. Keusch, M. C. Carey, Effects of bile and bile salts on growth and membrane lipid uptake by Giardia lamblia. Possible implications for pathogenesis of intestinal disease. J. Clin. Invest. 76, 1727-1732 (1985).

29. M.-A. Travers, C. Sow, S. Zirah, C. Deregnaucourt, S. Chaouch, R. M. Queiroz, S. Charneau, T. Allain, I. Florent, P. Grellier, Deconjugated bile salts produced by extracellular bile-salt hydrolase-like activities from the probiotic Lactobacillus johnsonii La1 inhibit Giardia duodenalis in vitro growth. Front. Microbiol. 7, 1453 (2016).

30. C. E. Halliday, C. Clark, M. J. Farthing, Giardia-bile salt interactions in vitro and in vivo. Trans. R. Soc. Trop. Med. Hyg. 82, 428-432 (1988).

31. M. J. Farthing, S. R. Varon, G. T. Keusch, Mammalian bile promotes growth of Giardia lamblia in axenic culture. Trans. R. Soc. Trop. Med. Hyg. 77, 467-469 (1983).

32. S. M. Dann, C. F. Manthey, C. Le, Y. Miyamoto, L. Gima, A. Abrahim, A. T. Cao, E. M. Hanson, J. K. Kolls, E. Raz, Y. Cong, L. Eckmann, IL-17A promotes protective IgA responses and expression of other potential effectors against the lumen-dwelling enteric parasite Giardia. Exp. Parasitol. 156, 68-78 (2015).

33. J. J. Smit, A. H. Schinkel, R. P. Oude Elferink, A. K. Groen, E. Wagenaar, L. van Deemter, C. A. Mol, R. Ottenhoff, N. M. van der Lugt, M. A. van Roon, M. A. van der Valk, G. J. A. Offerhaus, A. J. M. Berns, P. Borst, Homozygous disruption of the murine MDR2 P-glycoprotein gene leads to a complete absence of phospholipid from bile and to liver disease. Cell 75, 451-462 (1993).

34. L. V. Blanton, M. J. Barratt, M. R. Charbonneau, T. Ahmed, J. I. Gordon, Childhood undernutrition, the gut microbiota, and microbiota-directed therapeutics. Science 352, 1533 (2016).

35. O. Paerewijck, B. Maertens, A. Gagnaire, K. De Bosscher, P. Geldhof, Delayed development of the protective IL-17A response following a Giardia muris infection in neonatal mice. Sci. Rep. 9, 8959 (2019).

36. N. R. Barash, J. G. Maloney, S. M. Singer, S. C. Dawson, Giardia alters commensal microbial diversity throughout the murine gut. Infect. Immun. 85, e00948-16 (2017).

37. K. Wegner, S. Just, L. Gau, H. Mueller, P. Gérard, P. Lepage, T. Clavel, S. Rohn, Rapid analysis of bile acids in different biological matrices using LC-ESI-MS/MS for the investigation of bile acid transformation by mammalian gut bacteria. Anal. Bioanal. Chem. 409, 1231-1245 (2017).

38. S. I. Sayin, A. Wahlström, J. Felin, S. Jäntti, H. U. Marschall, K. Bamberg, B. Angelin, T. Hyötyläinen, M. Orešič, F. Bäckhed, Gut microbiota regulates bile acid metabolism by reducing the levels of tauro-beta-muricholic acid, a naturally occurring FXR antagonist. Cell Metab. 17, 225-235 (2013).

39. E. Tomlinson, L. Fu, L. John, B. Hultgren, X. Huang, M. Renz, J. P. Stephan, S. P. Tsai, L. Powell-Braxton, D. French, T. A. Stewart, Transgenic mice expressing human fibroblast growth factor-19 display increased metabolic rate and decreased adiposity. Endocrinology 143, 1741-1747 (2002).

40. M. R. Soeters, H. P. Sauerwein, M. Duran, R. J. Wanders, M. T. Ackermans, E. Fliers, S. M. Houten, M. J. Serlie, Muscle acylcarnitines during short-term fasting in lean healthy men. Clin. Sci. 116, 585-592 (2009).

41. R. Lehmann, X. Zhao, C. Weigert, P. Simon, E. Fehrenbach, J. Fritsche, J. Machann, F. Schick, J. Wang, M. Hoene, E. D. Schleicher, H. U. Häring, G. Xu, A. M. Niess, Medium chain acylcarnitines dominate the metabolite pattern in humans under moderate intensity exercise and support lipid oxidation. PLOS ONE 5, e11519 (2010).

42. R. D. Semba, I. Trehan, X. Li, R. Moaddel, M. I. Ordiz, K. M. Maleta, K. Kraemer, M. Shardell, L. Ferrucci, M. Manary, Environmental enteric dysfunction is associated with carnitine deficiency and altered fatty acid oxidation. EBioMedicine 17, 57-66 (2017).

43. B. Hogan, D. Eibach, R. Krumkamp, N. Sarpong, D. Dekker, B. Kreuels, O. Maiga-Ascofaré, K. Gyau Boahen, C. Wiafe Akenten, Y. Adu-Sarkodie, E. Owusu-Dabo, J. May; Fever Without Source (FWS) Study Group, L. Ammer, N. Struck, A. Hahn, W. Herr, A. Jaeger, V. Levermann, W. Loag, E. Mertens, L. Reigl, S. Steierberg, D. Winter, H. al-Emran, H. O. Boateng, T. Rettig, T. Binger, H. Hanson, K. Oppong, M. Nagel, M. Aepfelbacher, H. Buehl, B. Henrichfreise, D. Cadar, I. Eckerle, C. Drosten, H. Ittrich, E. Tannich, A. Thielebei, Malaria coinfections in febrile pediatric inpatients: A hospital-based study from Ghana. Clin. Infect. Dis. 66, 1838-1845 (2018).

44. I. Koruk, Z. Simsek, S. Tekin Koruk, N. Doni, G. Gürses, Intestinal parasites, nutritional status and physchomotor development delay in migratory farm worker's children. Child Care Health Dev. 36, 888-894 (2010).

45. G. H. Ettehad, A. Daryani, A. Nemati, Effect of Giardia infection on nutritional status in primary schoolchildren, in northwest Iran. Pak. J. Biol. Sci. 13, 229-234 (2010).

46. D. Fraser, N. Bilenko, R. J. Deckelbaum, R. Dagan, J. El-On, L. Naggan, Giardia lamblia carriage in Israeli Bedouin infants: Risk factors and consequences. Clin. Infect. Dis. 30, 419-424 (2000).
47. R. Ignatius, J. B. Gahutu, C. Klotz, C. Steininger, C. Shyirambere, M. Lyng, A. Musemakweri, T. Aebischer, P. Martus, G. Harms, F. P. Mockenhaupt, High prevalence of Giardia duodenalis assemblage $B$ infection and association with underweight in Rwandan children. PLOS Negl. Trop. Dis. 6, e1677 (2012).

48. M. J. Farthing, L. Mata, J. J. Urrutia, R. A. Kronmal, Natural history of Giardia infection of infants and children in rural Guatemala and its impact on physical growth. Am. J. Clin. Nutr. 43, 395-405 (1986)

49. Z. Simsek, F. Y. Zeyrek, M. A. Kurcer, Effect of Giardia infection on growth and psychomotor development of children aged 0-5 years. J. Trop. Pediatr. 50, 90-93 (2004).

50. D. S. Berkman, A. G. Lescano, R. H. Gilman, S. L. Lopez, M. M. Black, Effects of stunting, diarrhoeal disease, and parasitic infection during infancy on cognition in late childhood: A follow-up study. Lancet 359, 564-571 (2002).

51. A. G. Buret, Mechanisms of epithelial dysfunction in giardiasis. Gut 56, 316-317 (2007).

52. S. Solaymani-Mohammadi, S. M. Singer, Host immunity and pathogen strain contribute to intestinal disaccharidase impairment following gut infection. J. Immunol. 187, 3769-3775 (2011).

53. S. Das, T. Stevens, C. Castillo, A. Villasenõr, H. Arredondo, K. Reddy, Lipid metabolism in mucous-dwelling amitochondriate protozoa. Int. J. Parasitol. 32, 655-675 (2002).

54. M. Yichoy, T. T. Duarte, A. De Chatterjee, T. L. Mendez, K. Y. Aguilera, D. Roy, S. Roychowdhury, S. B. Aley, S. Das, Lipid metabolism in Giardia: A post-genomic perspective. Parasitology 138, 267-278 (2011).

55. E. Li, A. Zhao, T. Shea-Donohue, S. M. Singer, Mast cell-mediated changes in smooth muscle contractility during mouse giardiasis. Infect. Immun. 75, 4514-4518 (2007).

56. E. W. Mohareb, E. J. Rogers, E. J. Weiner, J. I. Bruce, Giardia lamblia: Phospholipid analysis of human isolates. Ann. Trop. Med. Parasitol. 85, 591-597 (1991).

57. D. S. Reiner, C.-S. Wang, F. D. Gillin, Human milk kills Giardia lamblia by generating toxic lipolytic products. J. Infect. Dis. 154, 825-832 (1986).

58. J. F. Markworth, B. Durainayagam, V. C. Figueiredo, K. Liu, J. Guan, A. K. H. MacGibbon B. Y. Fong, A. C. Fanning, A. Rowan, P. McJarrow, D. Cameron-Smith, Dietary supplementation with bovine-derived milk fat globule membrane lipids promotes neuromuscular development in growing rats. Nutr. Metab. 14, 9 (2017).

59. R. Hegner, L. Eskridge, The influence of bile salts on Giardia infections in rats. Am. J. Epidemiol. 26, 186-192 (1937).

60. B. D. Mata-Cárdenas, M. E. Hernández-García, F. González-Salazar, J. N. Garza-González, R. Palacios-Corona, E. I. Cortés-Gutiérrez, J. Vargas-Villarreal, Axenic cultivation and comparative phospholipase $\mathrm{A}_{2}$ activity of Giardia duodenalis in a serum-free medium. Acta Parasitol. 57, 211-215 (2012).

61. M. Camilleri, Bile acid diarrhea: Prevalence, pathogenesis, and therapy. Gut Liver $\mathbf{9}$, 332-339 (2015).

62. K. H. Kim, S. Choi, Y. Zhou, E. Y. Kim, J. M. Lee, P. K. Saha, S. Anakk, D. D. Moore, Hepatic FXR/SHP axis modulates systemic glucose and fatty acid homeostasis in aged mice. Hepatology 66, 498-509 (2017).

63. B. M. Owen, D. J. Mangelsdorf, S. A. Kliewer, Tissue-specific actions of the metabolic hormones FGF15/19 and FGF21. Trends Endocrinol. Metab. 26, 22-29 (2015).

64. K. R. Markan, M. J. Potthoff, Metabolic fibroblast growth factors (FGFs): Mediators of energy homeostasis. Semin. Cell Dev. Biol. 53, 85-93 (2016).

65. M. R. Torres, M. E. Silva, E. C. Vieira, E. A. Bambirra, M. I. Sogayar, F. J. Pena, J. R. Nicoli, Intragastric infection of conventional and germfree mice with Giardia lamblia. Braz. J. Med. Biol. Res. 25, 349-352 (1992).

66. M. F. Torres, A. P. T. Uetanabaro, A. F. Costa, C. A. Alves, L. M. Farias, E. A. Bambirra, F. J. Penna, E. C. Vieira, J. R. Nicoli, Influence of bacteria from the duodenal microbiota of patients with symptomatic giardiasis on the pathogenicity of Giardia duodenalis in gnotoxenic mice. J. Med. Microbiol. 49, 209-215 (2000).

67. N. Sillner, A. Walker, W. Koch, M. Witting, P. Schmitt-Kopplin, Metformin impacts cecal bile acid profiles in mice. J. Chromatogr. B 1083, 35-43 (2018).

68. Á. Kenéz, S. Dänicke, U. Rolle-Kampczyk, M. von Bergen, K. Huber, A metabolomics approach to characterize phenotypes of metabolic transition from late pregnancy to early lactation in dairy cows. Metabolomics 12, 165 (2016).

69. J. J. Verweij, R. A. Blangé, K. Templeton, J. Schinkel, E. A. Brienen, M. A. van Rooyen, L. van Lieshout, A. M. Polderman, Simultaneous detection of Entamoeba histolytica, Giardia lamblia, and Cryptosporidium parvum in fecal samples by using multiplex real-time PCR. J. Clin. Microbiol. 42, 1220-1223 (2004).

70. K. Zhang, A. Riba, M. Nietschke, N. Torow, U. Repnik, A. Pütz, M. Fulde, A. Dupont, M. Hensel, M. Hornef, Minimal SPI1-T3SS effector requirement for Salmonella enterocyte invasion and intracellular proliferation in vivo. PLOS Pathog. 14, e1006925 (2018).

71. A. Salonen, J. Nikkilä, J. Jalanka-Tuovinen, O. Immonen, M. Rajilić-Stojanović, R. A. Kekkonen, A. Palva, W. M. de Vos, Comparative analysis of fecal DNA extraction methods with phylogenetic microarray: Effective recovery of bacterial and archaeal DNA using mechanical cell lysis. J. Microbiol. Methods 81, 127-134 (2010). 
72. J. G. Caporaso, C. L. Lauber, W. A. Walters, D. Berg-Lyons, C. A. Lozupone, P. J. Turnbaugh, N. Fierer, R. Knight, Global patterns of $16 \mathrm{~S}$ rRNA diversity at a depth of millions of sequences per sample. Proc. Natl. Acad. Sci. U.S.A. 108 (suppl 1), 4516-4522 (2011).

73. J. G. Caporaso, C. L. Lauber, W. A. Walters, D. Berg-Lyons, J. Huntley, N. Fierer, S. M. Owens, J. Betley, L. Fraser, M. Bauer, N. Gormley, J. A. Gilbert, G. Smith, R. Knight, Ultra-highthroughput microbial community analysis on the Illumina HiSeq and MiSeq platforms. ISME J. 6, 1621-1624 (2012).

74. I. Lagkouvardos, D. Joseph, M. Kapfhammer, S. Giritli, M. Horn, D. Haller, T. Clavel, IMNGS: A comprehensive open resource of processed 16S rRNA microbial profiles for ecology and diversity studies. Sci. Rep. 6, 33721 (2016).

75. I. Lagkouvardos, S. Fischer, N. Kumar, T. Clavel, Rhea: A transparent and modular R pipeline for microbial profiling based on $16 \mathrm{~S}$ rRNA gene amplicons. Peer J. 5, e2836 (2017).

76. J. Chen, K. Bittinger, E. S. Charlson, C. Hoffmann, J. Lewis, G. D. Wu, R. G. Collman, F. D. Bushman, H. Li, Associating microbiome composition with environmental covariates using generalized UniFrac distances. Bioinformatics 28, 2106-2113 (2012).

77. F. Gremse, B. Theek, S. Kunjachan, W. Lederle, A. Pardo, S. Barth, T. Lammers, U. Naumann, F. Kiessling, Absorption reconstruction improves biodistribution assessment of fluorescent nanoprobes using hybrid fluorescence-mediated tomography. Theranostics 4, 960-971 (2014).

78. F. Gremse, D. Doleschel, S. Zafarnia, A. Babler, W. Jahnen-Dechent, T. Lammers, W. Lederle, F. Kiessling, Hybrid $\mu$ CT-FMT imaging and image analysis. J. Vis. Exp. 100, e52770 (2015).

Acknowledgments: We thank R. Holland, D. Gütle, T. Albers, and J. Möllmann for technical support; A. Dupont and L. Rüttger for help with animal breeding and mouse experiments; and M. Lehrke (RWTH Aachen University Hospital) and E. Tannich (Bernhard Nocht Institute, Hamburg, Germany) for helpful discussions. K.H. currently works as a Research Associate at Child Health BC, Provincial Health Services Authority, Vancouver, British Columbia, Canada. Funding: This work was supported by the priority program SPP1656 (HO2236/9-2 to M.W.H. and BL953/5-2 to André B.); the research grants HO2236/14-1, HO2236/17-1 (to M.W.H.), and TO1052/1-1 (to N.T.); and the Collaborative Research Centers CRC1382 (project ID 403224013-SFB 1382 projects B1, A5, A8, and Q1 to M.W.H., M.v.B., C.T., F.K., and F.G.), CRC900 (project C2 to B.S.), and CRC1371 (project P13 to M.K.) from the German Research Foundation (DFG). The study was further supported by a grant (E8-13) from the
Interdisciplinary Center for Clinical Research within the Faculty of Medicine at RWTH Aachen University (to F.G. and F.K.). We also acknowledge support from the Cluster of Excellence RESIST (EXC 2155), Hannover Medical School (MHH); the German Centre for Infection Research (DZIF), Partner Site Hannover-Braunschweig; the Center for Systems Neuroscience (ZSN), Hannover, Germany; and Niedersachsen-Research Network on Neuroinfectiology (N-RENNT). Electron microscopy data were generated by the Research Core Unit Electron Microscopy at the Hannover Medical School, Hannover, Germany. Author contributions: A.R. and K.H. performed and analyzed in vitro and in vivo infection experiments. D.v.Z., T.A., and A.R. performed in vitro growth experiments and performed quantitative PCR analysis. A.W., N.S., U.R.-K., P.S.-K., and M.v.B. performed lipid analyses. A.R., M.W.H., N.T., M.B., and A. Bleich performed gut microbiota transfer experiments to germ-free mice. N.v.B. analyzed the enteric microbiota composition. N.T. performed and analyzed the flow cytometric analysis. R.B., A. Binz, and B.S. performed electron microscopy imaging. S.R., F.G., and F.K. performed and analyzed whole-body imaging. S.M. and M.K. performed and analyzed the bomb calorimetric analysis. D.E., O.M.-A., and J.M. performed the human pediatric cohort study and provided the serum samples. A.M. and C.T. provided support with the animal experiments. K.H., A.R., and M.W.H. supervised the study. M.W.H. and A.R. wrote the paper. Competing interests: F.G. is the founder and owner of Gremse-IT GmbH, a spin-off company that develops software tools for medical image analysis. F.G. consults for MILabs B.V., Utrecht, Netherlands. The other authors declare that they have no competing interests. Data and materials availability: All data associated with this study are present in the paper or the Supplementary Materials. The V4 16S rDNA bacterial sequences used in this paper have been submitted to the Qiita and ENA databases under accession nos. 11423 and ERP105004, respectively.

Submitted 11 July 2019

Resubmitted 6 January 2020

Accepted 11 May 2020

Published 14 October 2020

10.1126/scitransImed.aay7019

Citation: A. Riba, K. Hassani, A. Walker, N. van Best, D. von Zeschwitz, T. Anslinger, N. Sillner, S. Rosenhain, D. Eibach, O. Maiga-Ascofaré, U. Rolle-Kampczyk, M. Basic, A. Binz, S. Mocek, B. Sodeik, R. Bauerfeind, A. Mohs, C. Trautwein, F. Kiessling, J. May, M. Klingenspor, F. Gremse, P. Schmitt-Kopplin, A. Bleich, N. Torow, M. von Bergen, M. W. Hornef, Disturbed gut microbiota and bile homeostasis in Giardia-infected mice contributes to metabolic dysregulation and growth impairment. Sci. Transl. Med. 12, eaay7019 (2020). 


\section{Science Translational Medicine}

\section{Disturbed gut microbiota and bile homeostasis in Giardia-infected mice contributes to metabolic dysregulation and growth impairment}

Ambre Riba, Kasra Hassani, Alesia Walker, Niels van Best, Dunja von Zeschwitz, Teresa Anslinger, Nina Sillner, Stefanie Rosenhain, Daniel Eibach, Oumou Maiga-Ascofaré, Ulrike Rolle-Kampczyk, Marijana Basic, Anne Binz, Sabine Mocek, Beate Sodeik, Rudolf Bauerfeind, Antje Mohs, Christian Trautwein, Fabian Kiessling, Jürgen May, Martin Klingenspor, Felix Gremse, Philippe Schmitt-Kopplin, André Bleich, Natalia Torow, Martin von Bergen and Mathias W. Hornef

Sci Transl Med 12, eaay7019.

DOI: $10.1126 /$ scitransImed.aay 7019

\section{A parasite's bilious defense}

The enteropathogenic parasite Giardia lamblia is a frequent cause of self-limited diarrhea in infected adult travelers. In contrast, parasite infection of children in endemic areas is not associated with diarrheal disease but rather with reduced growth and body weight gain. Riba et al. established a G. lamblia infection model in neonatal mice. Infected neonatal animals displayed reduced growth and weight gain. Analysis of these animals showed that $G$. lamblia induced bile secretion and that an altered gut microbiota composition, bile acid modification by commensal bacteria, and subsequent alterations of lipid metabolism contributed to this phenotype.

ARTICLE TOOLS

http://stm.sciencemag.org/content/12/565/eaay7019

SUPPLEMENTARY MATERIALS

RELATED CONTENT

REFERENCES

PERMISSIONS
http://stm.sciencemag.org/content/suppl/2020/10/09/12.565.eaay7019.DC1 http://stm.sciencemag.org/content/suppl/2020/10/09/12.565.eaay7019.DC2

\begin{abstract}
http://stm.sciencemag.org/content/scitransmed/12/563/eaba8412.full http://stm.sciencemag.org/content/scitransmed/12/551/eaax2220.full http://science.sciencemag.org/content/sci/370/6515/402.full http://science.sciencemag.org/content/sci/370/6515/467.full http://science.sciencemag.org/content/sci/371/6527/344.full http://science.sciencemag.org/content/sci/371/6527/400.full
\end{abstract}

This article cites 78 articles, 9 of which you can access for free http://stm.sciencemag.org/content/12/565/eaay7019\#BIBL

http://www.sciencemag.org/help/reprints-and-permissions

Science Translational Medicine (ISSN 1946-6242) is published by the American Association for the Advancement of Science, 1200 New York Avenue NW, Washington, DC 20005. The title Science Translational Medicine is a registered trademark of AAAS.

Copyright (C 2020 The Authors, some rights reserved; exclusive licensee American Association for the Advancement of Science. No claim to original U.S. Government Works 